\title{
Data reconciliation and gross error detection in crude oil pre-heat trains undergoing shell-side and tube-side fouling deposition \\ DOI:
}

10.1016/j.energy.2019.06.119

\section{Document Version}

Accepted author manuscript

Link to publication record in Manchester Research Explorer

Citation for published version (APA):

Loyola Fuentes, J. (2019). Data reconciliation and gross error detection in crude oil pre-heat trains undergoing shell-side and tube-side fouling deposition. Energy. https://doi.org/10.1016/j.energy.2019.06.119

\section{Published in:}

Energy

\section{Citing this paper}

Please note that where the full-text provided on Manchester Research Explorer is the Author Accepted Manuscript or Proof version this may differ from the final Published version. If citing, it is advised that you check and use the publisher's definitive version.

\section{General rights}

Copyright and moral rights for the publications made accessible in the Research Explorer are retained by the authors and/or other copyright owners and it is a condition of accessing publications that users recognise and abide by the legal requirements associated with these rights.

\section{Takedown policy}

If you believe that this document breaches copyright please refer to the University of Manchester's Takedown Procedures [http://man.ac.uk/04Y6Bo] or contact uml.scholarlycommunications@manchester.ac.uk providing relevant details, so we can investigate your claim.

\section{OPEN ACCESS}




\title{
Data Reconciliation and Gross Error Detection in Crude Oil Pre-Heat Trains Undergoing Shell-side and Tube-side Fouling Deposition
}

\author{
José Loyola-Fuentes*, Robin Smith \\ Centre for Process Integration, School of Chemical Engineering and Analytical Science, The University of Manchester, M13 \\ $9 P L, U K$
}

\begin{abstract}
Fouling is a problem in crude oil refineries. The effect of fouling deposition is particularly significant in the heat exchanger network (or pre-heat train) upstream of the crude oil distillation unit. A wide variety of semi-empirical models are available for predicting the fouling behaviour. These models can be obtained by fitting experimental or industrial operating data to a specific fouling model. When industrial data are used, the effect of measurement error and presence of faulty instruments (or gross errors) should be accounted for. This work presents a new methodology that allows for data reconciliation and gross error detection, together with the estimation of fouling model parameters for a pre-heat train undergoing different fouling mechanisms on the shell and tube-sides. The methodology is tested in a simulated case study. It is shown that the data reconciliation and gross error detection algorithms are able to minimise the measurement errors and to identify the presence of single or multiple faulty instruments. The fouling models for each heat exchanger are estimated using the reconciled data, and the fouling behaviour and thermal performance of the network are predicted and analysed.
\end{abstract}

Keywords: Heat Exchanger Network, Optimisation, Energy Recovery, Process Integration

\section{Highlights}

- Heat exchanger network simulation including accumulation of fouling resistance values over time

- Different fouling mechanisms are applied to different heat exchangers within the network

- Identification and estimation of single or multiple miscalibrations in measured data

- Parameter estimation for back-calculating fouling model parameters

\footnotetext{
*Corresponding author

Email address: jose.loyolafuentes@manchester.ac.uk (José Loyola-Fuentes)
} 


\section{Introduction}

Crude oil continues to be the major contributor and most exploited resource for the production of fuel and petrochemicals [1]. Its global importance has driven past and current research to develop methodologies for improving the design and operability of refining processes. One of the foremost improvements in terms of energy savings has been the development and implementation of heat integration in the pre-heating of crude oil. This pre-heating system is commonly known as the pre-heat train and consists of a heat exchanger network (HEN) of shell-and-tube heat exchangers (in most cases) interconnected in series and/or parallel arrangements, as it is illustrated in Figure 1. The pre-heat train is able to recover between 60 and $70 \%$ of the energy needed for the pre-heating of crude oil [2]. However, the performance of any heat exchanger and heat exchanger network is affected by fouling deposition. Its occurrence not only has a detrimental effect on the thermal performance of the energy recovery system, but also increases the pressure drop across the network, potentially leading to critical failure when no maintenance actions are considered.

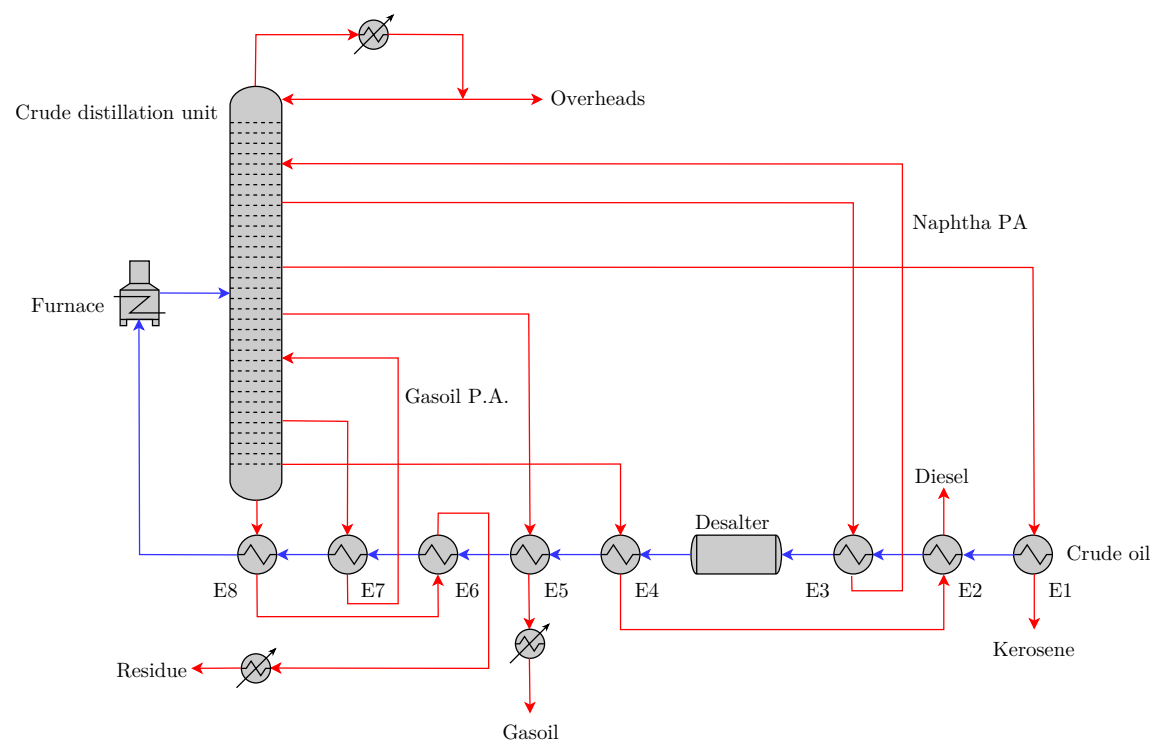

Figure 1: Crude Oil Pre-heat Train, based on Ahmad et. al [3]

In the pre-heat train, crude oil increases its temperature progressively, absorbing heat from several side products of the crude distillation unit, or CDU (Kerosene, Diesel, Heavy and Light Naphtha, etc.). As temperature increases, different fouling mechanisms combine together, contributing to the overall fouling resistance in each heat exchanger [4]. To date, several fouling mechanisms have been identified [5]. It has been found $[6,7,8]$ that these mechanisms depend on the crude oil chemical composition, physical properties and the HEN operating conditions. In general, more focus is given to the hot end of pre-heat trains, where chemical reaction fouling is the dominant mechanism, due to the high temperatures crude oil is pre-heated to. On the other hand, at the cold end, a decrease in thermal performance in one heat exchanger is partially 
compensated by the heat recovery downstream of that heat exchanger, as the temperature difference between cold and hot streams becomes higher [9].

Fouling is a complex phenomenon. Detailed information is needed for simultaneous understanding of the underlying causes and predicting fouling deposition in single and multiple heat exchangers. In the case of crude oil refineries, plant monitoring is increasingly becoming a standard practice for capturing and analysing fouling behaviour [10]. The use of field-data in modelling, control and optimisation of processes brings several advantages. First, it provides a more realistic context as to the state of equipment. Second, it allows for a rigorous model validation, as monitored data can be compared with the model predictions. Finally, the implementation of process monitoring improves crucial business activities such as production planning and risk assessments.

One of the major challenges when monitoring industrial processes through measured data is the presence of measurement error. Different types of measurement instruments are used in pipelines, equipment and storage units. A wide variety of technologies is available for measuring key operational variables (i.e. mass or volumetric flow rates, temperatures, pressures). Orifice-plate, magnetic and ultrasonic flow-meters can be used for measuring flow rates in pipes; temperature is monitored using thermal sensors and transmitters, and similar instruments can be used for pressure or pressure drop measurements. These numerous types of instruments differ in their corresponding accuracy. Although some specific instruments present relatively high measurement-accuracy, they can be affected by systematic errors (or gross errors). In most cases, these systematic errors are manifested in the form of measurement bias, equipment leaking or even complete failure due to environmental factors [11].

Data reconciliation (DR) has proven to be a useful tool for minimising the effect of measurement error in industrial and academic applications $[12,13]$. This data processing technique exploits the existing system redundancy from measured data to adjust and estimate relevant process data that satisfy specific system constraints (i.e. mass and energy balance) [14]. The estimations of the reconciled data are obtained via a minimisation problem that involves the redundant measured data and estimations of the measurements standard deviations. It is assumed that the measurement error consists in the sum of random and gross errors. Random errors are considered as a random variable following a normal Gaussian distribution with an expected value (mean) equal to zero [14]. In the case of gross errors, they can present a greater value than that of random errors. Gross errors alter the probability distribution of the measurement error, directly affecting the estimation of reconciled measurements in the data reconciliation problem.

The gross error detection (GED) problem is a problem related to the solution of the data reconciliation problem. The identification of faulty measurements or equipment leaks needs to be accounted for before implementing data reconciliation [14]. The GED problem can be mainly divided into two sub-problems. The first sub-problem is the detection of the presence of a gross error. The solution for this problem is achieved using statistical tests, which detect any deviation of the measurement errors from their corresponding prob- 
ability distribution. Examples of these tests for detecting the presence of gross errors are the Global Test [15], the Nodal Test [16], the Measurement Test [17] and the Generalized Likelihood Ratio (GLR) Test [18]. The second sub-problem is the simultaneous estimation of the location, type and numerical value of the gross error. After determining the presence of gross errors using one of the tests mentioned above, it is necessary to identify the measurement(s) containing gross error(s) or the process constraint containing an equipment leak. The estimation of the numerical value(s) of these gross errors is also needed. Several methods have been developed for addressing this sub-problem. In general, most of these estimation techniques are based on either recursive or combinatorial approaches. In the case of measurement biases, recursive serial elimination approaches [19] are a convenient option. These methods can be implemented for the identification of single or multiple gross errors, although they are not valid for identifying equipment leaks. Combinatorial methods such as the one developed by Sánchez et al. [20] presents enough flexibility for estimating measurement biases and process leaks. At the same time, their methodology is able to simultaneously solve the DR and GED problems by solving a DR problem for each combination of suspected candidates of measurements biases and process constraints for equipment leaks. The effect of equivalent sets of reconciled measurements (that is, sets of reconciled measurements presenting equal value of objective function) is also considered. However, the algorithm was developed for linear systems, where only mass balance equations are set as process constraints.

The accuracy of the different methods for the identification and estimation of gross errors can be tested and quantified using computational simulations [19]. Gross errors are manually added into a set of simulated data and after a series of trials where a specific GED method is applied, different performance indicators are calculated. A common indicator is the overall power function (OPF) [21], which is defined as the ratio between the number of simulation trials with perfect identification (that is, the location of a single or multiple gross error is correctly identified) and the total number of simulation trials.

The major challenge regarding fouling monitoring in crude oil refineries is the integration of rigorous dataprocessing techniques into the modelling and simulation of thermal equipment (i.e. heat exchanger networks). Smaili et al. [22] implemented a data-filtering approach as a data reconciliation method in the calculation of fouling model parameters. These fouling parameters were used in a cleaning schedule optimisation problem solved by a multi-start algorithm. Although economic savings are reported, most of these results were related to local optimum and the data-filtering was not well detailed. The importance of the application of these data-processing methods in crude oil refining processes is explained in the case study proposed by Ishiyama et al. [4]. In their study, a simulation of a crude oil pre-heat train was carried out; data reconciliation is applied by means of calculating an overall fouling resistance and comparing the estimations of missing temperatures with available plant-measurements. Fouling models were obtained by fitting the reconciled data with specific models within the simulation environment. Their methodology provides significant insights as to how important the implementation of data reconciliation is for fouling assessment. Nevertheless, their 
study did not consider the effect of gross errors within the data and fouling on both sides of each heat exchanger was ignored. A data reconciliation method based on matrix decomposition techniques (e.g. QR decomposition [19]) was implemented in an integrated methodology for simulation and optimisation of heat exchanger networks in the work presented by Ijaz et al. [23]. Linear models were used to formulate mass and energy balance equations, and an analytic solution for the data reconciliation problem was applied to estimate the reconciled measurements. The reconciled data presented good agreement compared with simulated measurements obtained from commercial software (i.e. Aspen HYSYS). However, fouling was not considered in both the heat exchanger network simulation and data reconciliation methods. Further applications can be found regarding the use of data reconciliation in different industrial processes such as crude oil refinery cracking units [24] and power plants [25].

The modelling, determination and prediction of fouling deposition in crude oil pre-heat trains has been extensively studied. Until recently, most of these studies have focused on the fouling phenomenon in the tube-side of heat exchangers. Some examples can be found in references [26, 27, 28]. Later studies have invested remarkable effort in the development of modelling frameworks for fouling in the shell-side of heat exchangers. In particular, the work proposed by Diaz-Bejarano et al. [29] is highlighted. The authors presented a dynamic model for shell-and-tube heat exchangers subject to shell-side and tube-side fouling. This model is locally distributed and incorporates the effects of flow patterns and clearance occlusions in the shell-side. Tube-side fouling is also considered by using a fouling threshold model, which was fitted using operational data, under a simple but functional filtering approach. Moreover, the implementation of hybrid optimisation techniques has proven to be a viable option for determining fouling model parameters in crude oil heat exchangers, as it was shown by Costa et al. [30].

In this paper, an integrated approach for determining fouling model parameters in a crude oil pre-heat train subject to fouling on both sides of each heat exchanger is proposed. Data reconciliation is applied and gross error detection is simultaneously implemented to account for the effect of any bias contained in single or multiple measurements. An optimisation-based parameter estimation is used for calculating the fouling model parameters. The generation of data and the prediction of the pre-heat train conditions (internal flow rates and temperatures) are performed via a matrix-based simulation strategy. The main results show this method's capability of reconciling process data including random and gross error, along with the identification of faulty instruments. Moreover, fouling is considered for shell-side and tube-side via fitted fouling rate models that are able to accurately predict fouling resistances and thermal performance of crude oil pre-heat trains. The potential of this methodology can be further exploited when designing and retrofitting heat exchanger networks and design of sensor networks when locating measurement instruments for fouling monitoring. 


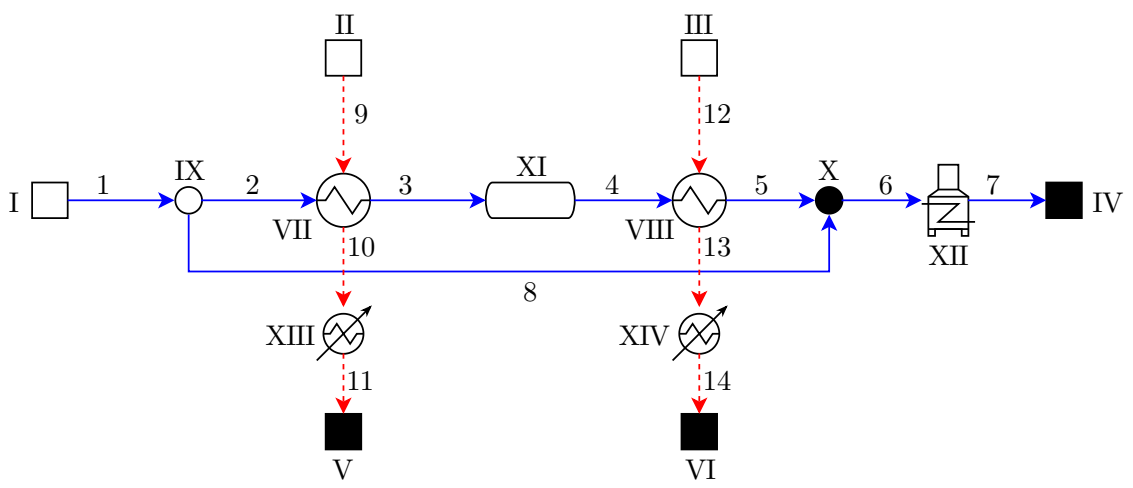

Figure 2: Simple HEN diagram: Cold streams - continuous lines, hot streams - dashed lines, supply units - white squares, demand units - black squares, mixer - black circle, splitter - white circle.

\section{HEN and Fouling Model}

The modelling and simulation of HENs subject to fouling are complex tasks. This complexity is directly related to the network's topology and physical restrictions such as the temperature-dependency of some key physical properties, namely the heat capacity and dynamic viscosity. Fouling should also be considered as a dynamic phenomenon, where all process-to-process heat exchangers in the network are subject to changes in their thermal performance, based on their corresponding values of fouling resistance. It is assumed that no phase change and pressure drop take place across the HEN. Stream interactions and different fouling mechanisms are accounted for in the modelling strategy described in Sections 2.1 and 2.2.

A flexible, matrix-based HEN-simulation strategy is used in this work. Linear equations are formulated for solving mass and energy balances. This matrix formulation was initially proposed by de Oliveira Filho et al. [31]. The network's structure is characterized by a directed graph, composed of vertices and edges. Vertices are described by supply and demand units at the beginning and end of the HEN ( $P S$ and $P D$ respectively), heat exchangers $(H E)$, splitters $(S P)$, mixers $(M X)$ and other unit operations $(U P)$. Edges are represented by cold $(c)$ and hot $(h)$ streams connecting one vertex to another. The inclusion of other unit operations (i.e. desalters, flash units) as well as cold and hot utilities ( $C U$ and $H U$ respectively) is considered by implementing the updated simulation strategy proposed by Ochoa-Estopier et al. [32]. An example of this characterisation is shown in Figure 2. The network in this figure consists of two heat exchangers, one splitter, one mixer, one desalter unit, two cold utilities, one hot utility, one cold process stream and two hot process streams. Each vertex is represented by a Roman numerical, whereas each edge in the network is represented by an Arabic number. The total number of elements in the HEN (i.e. vertices) is defined as $N$ and the total number of internal streams is defined as $S$.

The total number of vertices and edges are grouped according to the type of element and stream interconnected within the network. For vertices, the number of supply units $N^{P S}$, demand units $N^{P D}$, heat 


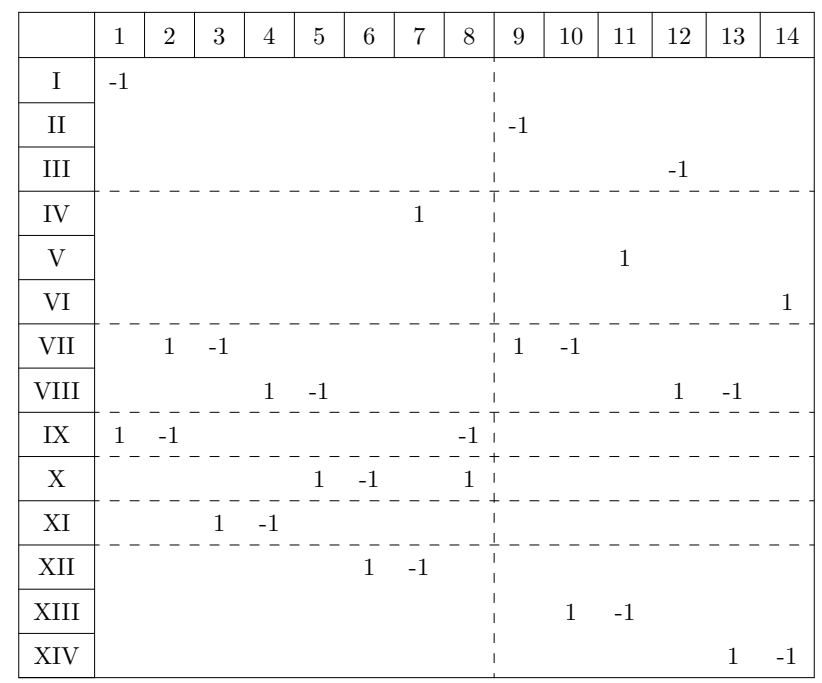

Figure 3: Incidence matrix for example in Figure 2

exchangers $N^{H E}$, splitters $N^{S P}$, mixers $N^{M X}$, unit operations $N^{U P}$, cold and hot utilities $N^{U T}$ (where $N^{U T}=N^{C U}+N^{H U}$ ) are used to describe each of these elements. The total number of streams is grouped according to the number of cold streams $S_{c}$ and hot streams $S_{h}$. The interactions within the network can be further represented using an incidence matrix $M$ of dimensions $(N \times S)$. The elements inside the matrix vary depending on each interaction. If an edge $j$ is directed to a vertex $i$, then $\left(\boldsymbol{M}_{i, j}\right)=1$. On the other hand, if an edge $j$ is directed from a vertex $i,(\boldsymbol{M})_{i, j}=-1$. The value of any other element $(\boldsymbol{M})_{i, j}$ is set to be zero otherwise. The previously described notation for each element and stream in the HEN is used for organising the incidence matrix, as it is shown in Equation 1. The corresponding incidence matrix for the network depicted in Figure 2 is detailed in Figure 3. For the sake of simplicity, null entries and utility streams (cold and hot) are omitted. The incidence matrix $\boldsymbol{M}$ is used for formulating the mass and energy conservation equations to solve for the values of internal flow rates and temperatures. This simple arrangement allows for fast calculations, improving the convergence of the simulation strategy.

$$
\boldsymbol{M}=\left[\begin{array}{c}
\boldsymbol{M}^{P S} \\
\boldsymbol{M}^{P D} \\
\boldsymbol{M}^{H E} \\
\boldsymbol{M}^{M X} \\
\boldsymbol{M}^{S P} \\
\boldsymbol{M}^{U P} \\
\boldsymbol{M}^{U T}
\end{array}\right]=\left[\begin{array}{ll}
\boldsymbol{M}_{c}^{P S} & \boldsymbol{M}_{h}^{P S} \\
\boldsymbol{M}_{c}^{P D} & \boldsymbol{M}_{h}^{P D} \\
\boldsymbol{M}_{c}^{H E} & \boldsymbol{M}_{h}^{H E} \\
\boldsymbol{M}_{c}^{M X} & \boldsymbol{M}_{h}^{M X} \\
\boldsymbol{M}_{c}^{S P} & \boldsymbol{M}_{h}^{S P} \\
\boldsymbol{M}_{c}^{U P} & \boldsymbol{M}_{h}^{U P} \\
\boldsymbol{M}_{c}^{U T} & \boldsymbol{M}_{h}^{U T}
\end{array}\right]
$$

For the mass balance, all internal and external flow rates are calculated using specific input information. 
Internal and external flow rates are represented by the vectors $\boldsymbol{m}$ (dimension $S \times 1$ ) and $\boldsymbol{n}$ (dimension $\left.\left(N^{P S}+N^{P D}\right) \times 1\right)$ respectively. Both vectors can be divided into cold and hot streams for vector $\boldsymbol{m}$

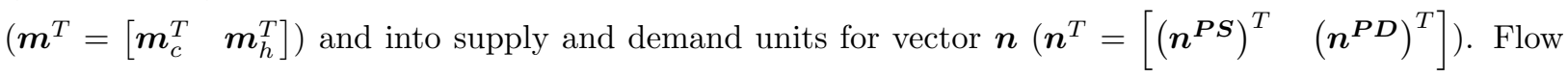
rate specifications related to the streams of each supply unit have known values and are represented by the vector $\left(\boldsymbol{n}^{P S}\right)^{*}$. Similarly, internal and external temperatures in the network are defined as vectors $\boldsymbol{T}$ (dimension $S \times 1)$ and $\boldsymbol{V}$ (dimension $\left(N^{P S}+N^{P D}\right) \times 1$ ) respectively. These two vectors are further divided into cold and hot streams for vector $\boldsymbol{T}\left(\boldsymbol{T}^{T}=\left[\begin{array}{ll}\boldsymbol{T}_{c}^{T} & \boldsymbol{T}_{h}^{T}\end{array}\right]\right)$ and into supply and demand units for vector $\boldsymbol{V}\left(\boldsymbol{V}^{T}=\left[\begin{array}{ll}\left(\boldsymbol{V}^{\boldsymbol{P S}}\right)^{T} & \left(\boldsymbol{V}^{\boldsymbol{P D}}\right)^{T}\end{array}\right]\right)$. Temperature specifications for the streams in each supply unit have known values, contained in the vector $\left(\boldsymbol{V}^{P S}\right)^{*}$. Mass and energy conservation equations are now formulated, assuming steady state and no mass and energy losses to the corresponding surroundings.

\subsection{Full HEN modelling}

The sets of mass and energy conservation equations are integrated into a set of two linear systems of equations. The first set is solved for the mass balance for vector $\boldsymbol{m}$ and it is shown in Equation 2, whereas the second one is solved for the energy balance for vector $\boldsymbol{T}$, which is defined in Equation 3.

$$
\begin{aligned}
& A x=b \\
& C z=d
\end{aligned}
$$

where the vectors $\boldsymbol{x}$ and $\boldsymbol{b}$ are defined in Equations 4 and 5. The vectors $\boldsymbol{z}$ and $\boldsymbol{d}$ are shown in Equations 6 and 7. The structure of matrices $\boldsymbol{A}$ and $\boldsymbol{C}$ are depicted in Figure 4 and 5 respectively. Details regarding the elements contained in each matrix are described in Appendix A.

$$
\begin{aligned}
& \boldsymbol{x}=\left[\begin{array}{c}
\boldsymbol{m} \\
\boldsymbol{n}
\end{array}\right]=\left[\begin{array}{c}
\boldsymbol{m}_{c} \\
\boldsymbol{m}_{h} \\
\boldsymbol{n}^{P S} \\
\boldsymbol{n}^{P D}
\end{array}\right] \\
& \boldsymbol{b}=\left[\begin{array}{c}
\mathbf{0} \\
\left(\boldsymbol{n}^{P S}\right)^{*}
\end{array}\right]
\end{aligned}
$$




$$
\begin{aligned}
& \boldsymbol{z}=\left[\begin{array}{c}
\boldsymbol{T} \\
\boldsymbol{V}
\end{array}\right]=\left[\begin{array}{c}
\boldsymbol{T}_{c} \\
\boldsymbol{T}_{h} \\
\boldsymbol{V}^{P S} \\
\boldsymbol{V}^{P D}
\end{array}\right] \\
& \boldsymbol{d}=\left[\begin{array}{c}
\mathbf{0} \\
\boldsymbol{\Delta} \boldsymbol{T}^{U P} \\
\boldsymbol{Q}^{U} \\
\boldsymbol{Q}^{U} \\
\left(\boldsymbol{V}^{P S}\right)^{*}
\end{array}\right]
\end{aligned}
$$

\begin{tabular}{|c|c|c|}
\hline & $M^{P S}$ & $\begin{array}{lll}\boldsymbol{I}^{P S} & \mathbf{0}\end{array}$ \\
\hline & $M^{P D}$ & $0 \quad 1-I^{P D}$ \\
\hline $\boldsymbol{M}_{c}^{H E}$ & 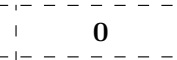 & ' \\
\hline 0 & $\boldsymbol{M}_{h}^{H E}$ & 0 \\
\hline---- & $M^{M X}$ & 0 \\
\hline & $M^{S P}$ & 0 \\
\hline $\operatorname{diag}(\phi$ & D) $\boldsymbol{M}_{+}^{S P}-\boldsymbol{S P}$ & 0 \\
\hline & $M^{U P}$ & 0 \\
\hline$M_{c}^{U T}$ & 0 & 0 \\
\hline 0 & $\boldsymbol{M}_{h}^{U T}$ & 0 \\
\hline & 0 & $\begin{array}{lll} & & 0 \\
\end{array}$ \\
\hline
\end{tabular}

Figure 4: Structure of coefficients for matrix $\boldsymbol{A}$

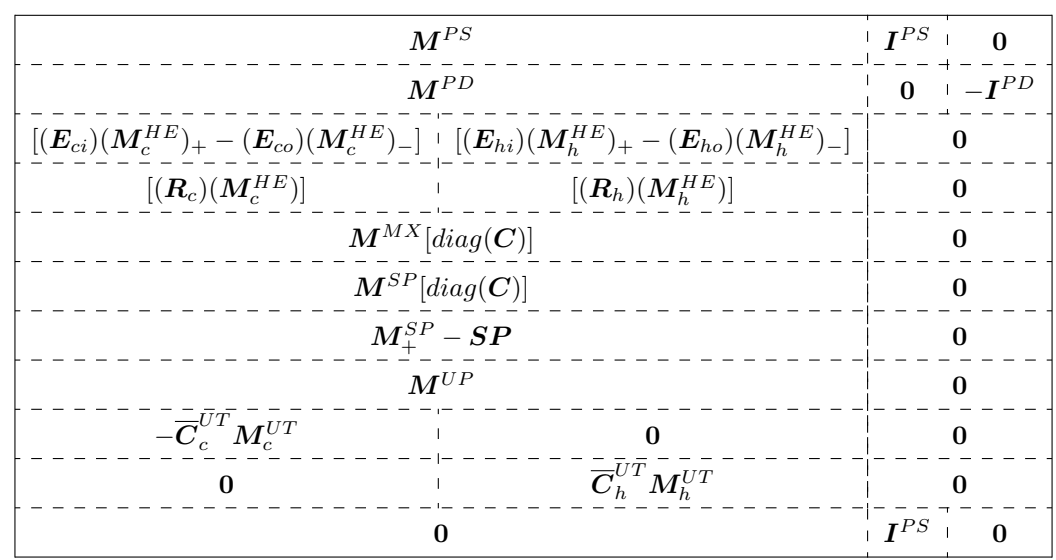

Figure 5: Structure of coefficients for matrix $C$ 


\subsection{Fouling Modelling and Simulation}

The fouling resistance $\left(R_{f}\right)$ for all process-to-process heat exchangers in the HEN are included in the main modelling framework by considering the contributions from shell-side and tube-side $\left(R_{f, \text { shell }}\right.$ and $R_{f, \text { tube }}$ respectively) in the value of the overall heat transfer coefficient $U_{d}$. These contributions are related to the value of $U_{d}$ in Equation 8. In this Equation, the thermal resistance attributed to the tube-wall is assumed to be negligible, compared to the thermal resistances due to fouling and heat convection. Note that when fouling does not occur in neither side of any heat exchanger, the overall heat transfer coefficient is defined as $U_{c}$, which denotes absence-of-fouling conditions.

$$
U_{d}=\left[\left(\frac{1}{h_{\text {tube }}}+R_{f, \text { tube }}\right)\left(\frac{d_{\text {out }}}{d_{\text {in }}}\right)+\left(\frac{1}{h_{\text {shell }}}+R_{f, \text { shell }}\right)\right]^{-1}
$$

where $h_{\text {tube }}$ and $h_{\text {shell }}$ are the local heat transfer coefficients for tube-side and shell-side respectively. Each coefficient is calculated using empirical correlations. These correlations depend on heat exchanger geometry and fluid physical properties. In this work, the correlations proposed by Wang et. al are used, as they provide confident and reliable results [33]. These correlations utilise detailed information related to tube-side and shell-side stream allocation, hydraulics and flow patterns caused by pitch selection and tube-bundle configurations. Additionally, the overall thermal resistance for the tube-side is adjusted using the outer-to-inner tube diameter $\left(d_{\text {out }} / d_{\text {in }}\right)$.

This work includes the accumulation of fouling over time in the HEN simulation by using fouling rate models and integrating these models over a specific time-span, divided in equally sized time-steps $\Delta t$. Different fouling mechanisms are considered in the shell-side and tube-side of all heat exchangers in the HEN. These fouling mechanisms also change along the pre-heat train, as the temperature of the crude oil progressively increases. The updating of the fouling resistance (shell-side or tube-side) for two consecutive time-intervals $(n-1)$ and $n$ is shown in Equation 9.

$$
\left.R_{f}\right|_{n-1}=\left.R_{f}\right|_{n}+\left.\Delta t \frac{d R_{f}}{d t}\right|_{n}
$$

Normally, deposition of waxes, together with chemical reaction fouling are more likely to occur in crude oil pre-heat trains [4]. These mechanisms are considered in this work by implementing a suitable fouling rate model for each mechanism in both sides of the heat exchangers within the pre-heat train. A simple, constant fouling rate model is selected to represent deposition of waxes, whereas the fouling model proposed by Polley et al. [9] is used for chemical reaction fouling. As no pressure drop is assumed within the HEN, the effects of friction factors into the severity of fouling are not considered. The selection of Polley's model is chosen over more rigorous fouling models (i.e. Yeap et al.[34]) based on this assumption. Both fouling models are shown Equations 10 and 11 respectively. 


$$
\begin{aligned}
& \frac{d R_{f}}{d t}=\alpha_{1} \\
& \frac{d R_{f}}{d t}=\alpha_{2} R e^{-0.80} \operatorname{Pr}^{-0.33} \exp \left(\frac{-E_{A}}{R_{g} T_{W}}\right)-\gamma R e^{0.80}
\end{aligned}
$$

where $\operatorname{Re}, \operatorname{Pr}, R_{g}$ and $T_{W}$ are the relevant Reynolds number, Prandtl number, the ideal gas constant and the tube-wall temperature. These parameters mainly depend on the system geometry and the corresponding physical properties, namely density $(\rho)$, specific heat $(c p)$, thermal conductivity $(\lambda)$ and viscosity $(\mu)$. The parameters $\alpha_{1}, \alpha_{2}, E_{A}$ and $\gamma$ are the specific fouling model parameters. Note that there is a strong dependency of the fouling rate in the chemical reaction model in Equation 11 with the relevant walltemperature $T_{W}$. The value of the wall temperature is non-uniform through a heat exchanger (either shell-side or tube-side). Therefore, a representative value is needed when calculating the fouling rate. A useful approximation for this representative temperature is to integrate the fouling rate along both ends of the heat exchanger wall. When chemical reaction fouling occurs in the tube-side of a heat exchanger, cold and hot end wall-temperatures can be estimated using Equations 12 and 13 respectively, where $T_{W, c}$ and $T_{W, h}$ are the wall temperatures at the cold and hot end of the tube-wall.

$$
\begin{aligned}
& T_{W, c}=T_{c, i}+\frac{T_{h, o}-T_{c, i}}{h_{\text {tube }}\left[\left(\frac{1}{h_{\text {tube }}}+R_{f, \text { tube }}\right) \frac{d_{\text {out }}}{d_{\text {in }}}+\frac{1}{h_{\text {shell }}}+R_{f, \text { shell }}\right]} \\
& T_{W, h}=T_{c, o}+\frac{T_{h, o}-T_{c, i}}{h_{\text {tube }}\left[\left(\frac{1}{h_{\text {tube }}}+R_{f, \text { tube }}\right) \frac{d_{\text {out }}}{d_{\text {in }}}+\frac{1}{h_{\text {shell }}}+R_{f, \text { shell }}\right]}
\end{aligned}
$$

The integrated fouling rate for chemical reaction in the tube-side is then calculated using Equation 14 [35]. In this work, the wall temperature range is divided into equally sized temperature sub-intervals and the trapezoidal rule is used for integrating the mean fouling rate value.

$$
\left.\frac{d R_{f}}{d t}\right|_{\text {mean }}=\frac{\int_{T_{W, c}}^{T_{W, h}} \frac{d R_{f}}{d t} d T_{W}}{T_{W, h}-T_{W, c}}
$$

\section{Data Reconciliation and Identification of Faulty Instruments}

The minimisation of measurement error in a specific set of data is to be obtained via data reconciliation. This method adjusts the values of measured variables in order to satisfy relevant process constraints such as mass and energy conservation equations [14]. In this work, a nonlinear data reconciliation problem is formulated and implemented to the HEN flow rates and temperatures. Each of these variables is considered to be a measurement from specific instruments presenting individual values of accuracy. 
The measurement error vector $(\boldsymbol{\xi})$ is defined as the difference between the vectors of measured $\left(\boldsymbol{x}_{\boldsymbol{m}}\right)$ and reconciled values $\left(\boldsymbol{x}_{\boldsymbol{r}}\right)$ in Equation 15. An alternative definition for the measurement error is shown in Equation 16, where $\boldsymbol{\xi}$ corresponds to the sum of two different types of errors, random error $\left(\boldsymbol{r}_{\boldsymbol{\xi}}\right)$ and gross error $\left(\boldsymbol{g}_{\boldsymbol{\xi}}\right)$.

$$
\begin{aligned}
& \xi=x_{m}-x_{r} \\
& \xi=r_{\xi}+g_{\xi}
\end{aligned}
$$

Random errors are defined as random events that can cause disruptions within the data. In the process industries, these errors are estimated using a normal probability distribution with zero mean and the within the range of \pm 3 times the standard deviation of the corresponding measurement instruments [14] $\left(\sigma_{m}\right.$ and $\sigma_{T}$ for flow rate and temperature measurements respectively). On the other hand, gross errors are produced by non-random events such as miscalibrations or instrumental malfunctions. The reconciliation of these two types of errors is necessary for reliable results, as the presence of measurement error in process data can mislead further calculations and process-related decisions such as maintenance and process control [19].

\subsection{Data Reconciliation Formulation}

In the absence of gross errors, the data reconciliation problem in a heat exchanger network is formulated as a nonlinear constrained minimisation problem, as shown in Equation 17. The general formulation in Equation 17 includes the vector of measured and unmeasured variables $\left(\boldsymbol{x}_{\boldsymbol{m}}\right.$ and $\boldsymbol{x}_{\boldsymbol{u}}$ respectively) and the covariance matrix $\boldsymbol{\psi}$, which is defined as a diagonal matrix containing the variance of each measured value in its main diagonal, as no statistical correlation among measurements is assumed. Note that the presence of unmeasured variables $\boldsymbol{x}_{\boldsymbol{u}}$ is not considered in this work, as this methodology assumes that all process variables are measured.

$$
\begin{array}{ll}
\min _{\boldsymbol{x}_{\boldsymbol{r}}} & \left(\boldsymbol{x}_{\boldsymbol{m}}-\boldsymbol{x}_{\boldsymbol{r}}\right)^{T} \boldsymbol{\psi}^{-1}\left(\boldsymbol{x}_{\boldsymbol{m}}-\boldsymbol{x}_{\boldsymbol{r}}\right) \\
\text { s.t. } & \boldsymbol{f}\left(\boldsymbol{x}_{\boldsymbol{r}}\right)=\mathbf{0} \\
& \boldsymbol{g}\left(\boldsymbol{x}_{\boldsymbol{r}}\right) \leq \mathbf{0}
\end{array}
$$

The vector of nonlinear constraints $\boldsymbol{f}\left(\boldsymbol{x}_{\boldsymbol{r}}\right)$ contains the mass and energy balances described in Section 2.1. The vector of inequality constrains $\boldsymbol{g}\left(\boldsymbol{x}_{\boldsymbol{r}}\right)$ is used for specifications of each flow rate and temperature measurement. Fouling is included in the reconciliation by adding a non-negativity constraint to the value of the measured overall fouling resistance $\left(R_{f}^{m s r}\right)$ for each set of measured data, following Equation 18, where $U_{c}$ is the overall heat transfer coefficient when no fouling is considered.

$$
R_{f}^{m s r}=\frac{1}{U_{d}}-\frac{1}{U_{c}} \geq 0
$$


In this work, Equation 17 is solved using Sequential Quadratic Programming (SQP), as it has been proven to present several advantages compared to other commonly used nonlinear programming methods, namely Generalised Reduced Gradient (GRG) [19].

\subsection{Gross Error Detection and Identification}

In this work, gross error in the form of measurement bias is considered. The key challenges are to identify if a given set of data contains a gross error (detection problem), to find the measurement(s) containing the gross error(s) (identification problem) and finally to estimate the value of such error(s) (estimation problem).

The detection problem is addressed using the global test [14]. This test uses a statistical test function $\tau$ that depends on the vector of constraints residuals $\boldsymbol{q}_{\xi}$. This test function is shown in Equation 19, where $\boldsymbol{\phi}_{\xi}$ is the covariance matrix of the constraint residuals vector. In this work, the equality constraints in vector $\boldsymbol{f}\left(\boldsymbol{x}_{\boldsymbol{r}}\right)$ is a representation of the linear formulations of mass and energy balances described in Section 2.1 .

$$
\tau=\boldsymbol{q}_{\xi}^{T} \boldsymbol{\phi}_{\xi}^{-1} \boldsymbol{q}_{\xi}
$$

When no gross errors are contained in the data, $\tau$ follows a chi-square distribution with $\nu$ degrees of freedom. The value of $\tau$ is compared with a threshold value $\tau_{c}=\chi_{(1-\delta)}^{2}(\nu)$, where $\delta$ is the chosen level of significance or confidence. If $\tau>\tau_{c}$, a gross error is detected. Otherwise, the global test is passed and no gross errors are present.

The identification and estimation problems are accounted for by using the simultaneous estimation of the location and value of gross errors proposed by Sánchez et al. [20]. A modified method is implemented in this work to integrate the use of nonlinear programming. As a first step, several gross error candidates are selected. The data reconciliation problem for each combination (single and multiple) of these gross errors is solved using SQP. The minimisation problem when considering measurement bias is shown in Equation 20, where the matrix $\boldsymbol{B}_{\xi}$ contains ones or zeros depending on the measurement in which the gross error(s) is contained. The number of rows of this matrix corresponds with the number of measurements, whereas the number of columns corresponds with the number of gross errors within the data-set.

$$
\begin{array}{ll}
\min _{\boldsymbol{x}_{r}, \boldsymbol{g}_{\boldsymbol{\xi}}} & \left(\boldsymbol{x}_{\boldsymbol{m}}-\boldsymbol{x}_{\boldsymbol{r}}-\boldsymbol{g}_{\xi} \boldsymbol{B}_{\xi}\right)^{T} \boldsymbol{\psi}^{-1}\left(\boldsymbol{x}_{\boldsymbol{m}}-\boldsymbol{x}_{\boldsymbol{r}}-\boldsymbol{g}_{\xi} \boldsymbol{B}_{\xi}\right) \\
\text { s.t. } & \boldsymbol{f}\left(\boldsymbol{x}_{\boldsymbol{r}}, \boldsymbol{g}_{\boldsymbol{\xi}}\right)=\mathbf{0} \\
& \boldsymbol{g}\left(\boldsymbol{x}_{\boldsymbol{r}}, \boldsymbol{g}_{\boldsymbol{\xi}}\right) \leq \mathbf{0}
\end{array}
$$

The global test is used as a stopping criterion and for the selection of the best combination of gross error that minimises the measurement error vector. Moreover, this work accounts for the presence of equivalent sets of gross errors, based on the definition proposed by Bagajewicz and Jiang [36], where two sets of gross errors are equivalent when they have the same effect in the data reconciliation problem (see Equation 
20). In cases when the minimum value of measurement error results from several equivalent sets, each of these sets is compared with additional information from the network (i.e. design flow rate and temperature specifications); the set presenting the lowest absolute difference is selected as the one containing the correct gross errors in the data set.

To quantify the performance of the gross error detection algorithm, simulation-based tests are carried out and the value of the overall power function (OPF) is used. This function is defined as the ratio between the number of simulations with perfect identification (the simulations where all gross error are located in their corresponding measurement); and the total number of simulations. This definition can be applied to scenarios a gross error is contained multiple measurements, where the maximum number of multiple gross errors that can be detected is limited to the existing number of units (i.e. heat exchangers, mixers, splitters and unit operations) [36].

\section{Parameter Estimation of Fouling Models}

The set of parameters in a fouling rate model, such as the ones presented in Equations 10 and 11, vary depending on the characteristics of the crude oil or crude oil blend. Thus, an adaptable method is needed to account for the changes in crude oil when process data are used. In this work, it is assumed that the available data for reconciliation and parameter estimation are based on daily averages indicating steady state conditions. Temperature-dependency can be considered for the crude oil and side-products physical properties. However, to establish a relationship between these properties and temperature is a complex task. Hence, the parameter estimation method described in this work considers constant values of physical properties.

\subsection{Problem Formulation}

Following the analysis provided in the methodology developed by Costa et al. [30], normalised fouling model parameters are defined for each fouling model, based on reported values for specific fouling rate models found in the available literature [9]. This normalised set of parameters is shown in Equations 21 to 24 , where the symbols $\left({ }^{\sim}\right)$ and $\left(^{\wedge}\right)$ denote normalised and fitted fouling model parameters respectively.

$$
\begin{array}{r}
\tilde{\alpha}_{1}=\frac{\hat{\alpha}_{1}}{\alpha_{1}} \\
\tilde{\alpha}_{2}=\frac{\hat{\alpha}_{2}}{\alpha_{2}} \\
\tilde{E}_{A}=\frac{\hat{E}_{A}}{E_{A}} \\
\tilde{\gamma}=\frac{\hat{\gamma}}{\gamma}
\end{array}
$$


The selected fouling models (see Equations 10 and 11) are re-formulated in order to include the new set of normalised parameters and the models are fitted to the reconciled values via the minimisation of the root mean square error between the fitted and measured fouling resistances $\left(R_{f}^{f i t}\right.$ and $R_{f}^{m s r}$ respectively), for each data-set representing a day of operation. The minimisation problem is shown in Equation 25, where $k$ is the total number of data-sets, and $n$ is a counter representing each data-set. The minimisation problem is subject to lower and upper bounds for each normalised fouling model parameter (contained in the vector $\boldsymbol{p})$ to account for different types of crude oil undergoing to the same fouling mechanisms. This feature is implemented as a modification from the original source, as the authors solved the parameter estimation problem using an un-bounded approach, only considering the tube-side of a single exchanger.

$$
\begin{array}{ll}
\min _{\boldsymbol{p}} & \sqrt{\frac{\sum_{n=1}^{k}\left(R_{f, n}^{m s r}-R_{f, n}^{f i t}(\boldsymbol{p})\right)}{k}} \\
\text { subject to } & \boldsymbol{p}^{L} \leq \boldsymbol{p} \leq \boldsymbol{p}^{U}
\end{array}
$$

\subsection{Optimisation Algorithm}

In order to avoid local optimality, a hybrid optimisation strategy consisting in the application of stochastic search and deterministic methods is used for the parameter estimation. The stochastic search implemented in this work is the Genetic Algorithm (GA) [37]. This solver has the advantage of not needing an initial guess, as it initially searches for a solution based on a random search around the solution-space. The selection of this algorithm is not strict to this specific one. However, it is desired to acheive a wide search to avoid local optimality and a stochastic search suits this particular aim. Hence, other alternative algorithms can be used for solving the problem defined in Equation 25. By applying lower and upper bounds, the algorithm looks for the best set of parameters that minimises the objective function in Equation 25. The set of parameters resulting from the Genetic Algorithm is then used as an initial guess for applying deterministic optimisation based on the interior point method. This hybrid approach is implemented in order to improve the likelihood of reaching a global optimum and for calculating the best set of fouling model parameters to predict and assess the fouling behaviour in a heat exchanger network.

\section{Case Study}

The methodology in this work is applied to predict the fouling behaviour and identify potential faulty instruments in a crude oil pre-heat train. The structure of this pre-heat train is based on the heat exchanger network shown in the work proposed by Ahmad et al. [3], and it is illustrated in Figure 6. The heat exchanger network consists of eight process-to-process heat exchangers, one desalter unit, three cold utilities and one hot utility. Initial operating and geometric data are illustrated in Tables 1 and Table 2 respectively. The data in Table 1 are used as supply unit specifications for the HEN simulation and data reconciliation 


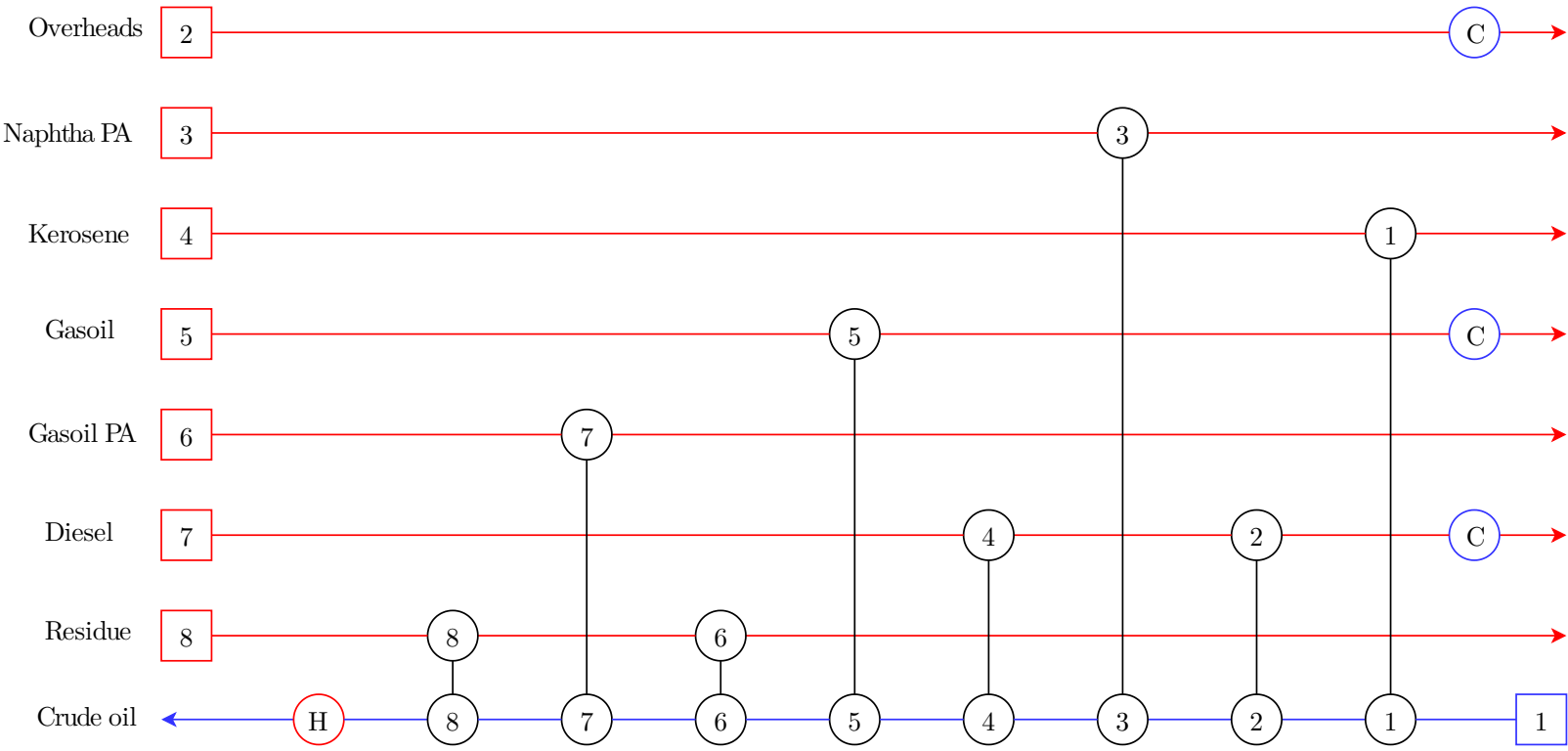

(H) Hot utility

(C) Cold utility

Figure 6: Pre-heat train structure for case study

of HEN inlets, after random and gross errors are added to the data. Hence, these values change within the time span. In the case of cold and hot utilities, inlet flow rates and temperatures, together with their corresponding heat duties are presented in Table 3. Physical properties for cold and hot streams in each exchanger are shown in Table 4. All process-to-process heat exchangers are subject to shell-side and tubeside fouling, where more than one mechanism can take place in a single heat exchanger. The effect of fouling on the pre-heat train's pressure drop is not considered. Crude oil goes through the tube side of the pre-heat train, whereas side-products from the CDU flow through the shell-side. The simulation and optimisation strategies in this work have been coded in MATLAB, using in-built functions for the optimisation methods.

In order to replicate the variability of an operating process, the simulation strategy described in Section 2.1 is used and measurement errors are added to the data. A simulation time of one year with time intervals of 24 hours are used, resulting in a total of 366 sets of steady-state daily-averaged measured data, where fouling progressively increases in each heat exchanger, as it is stated in Equation 9. It is assumed that all flow rates and temperatures are measured variables. Random and gross errors are added separately, as it is desired to identify the specific capabilities of both the data reconciliation and gross error detection algorithms. The values of the added random errors are generated using a normal probability distribution with known standard deviations via a random generator in MATLAB. The values of $\sigma_{m}$ and $\sigma_{T}$ are $1.50 \mathrm{~kg}$ $\mathrm{s}^{-1}$ and $1.50^{\circ} \mathrm{C}$ respectively. These values correspond with common magnitudes of accuracy in measurement 
Table 1: Input conditions for pre-heat train

\begin{tabular}{ccc}
\hline Stream & Inlet flow rate $\left(\mathrm{kg} \mathrm{s}^{-1}\right)$ & Inlet temperature $\left({ }^{\circ} \mathrm{C}\right)$ \\
\hline Crude oil & 194 & 10 \\
Naphtha P.A. & 288 & 160 \\
Kerosene & 18 & 210 \\
Gasoil & 36 & 260 \\
Gasoil P.A. & 144 & 280 \\
Diesel & 20 & 350 \\
Residue & 55 & 380 \\
\hline
\end{tabular}

Table 2: Geometric data for pre-heat train

\begin{tabular}{ccccccccc}
\hline & E1 & E2 & E3 & E4 & E5 & E6 & E7 & E8 \\
\hline Tube inner diameter (mm) & 15.4 & 15.4 & 15.4 & 15.4 & 15.4 & 15.4 & 15.4 & 15.4 \\
Tube outer diameter (mm) & 19.0 & 19.0 & 19.0 & 19.0 & 19.0 & 19.0 & 19.0 & 19.0 \\
Tube length (m) & 7.16 & 8.35 & 24.47 & 3.74 & 8.50 & 10.22 & 12.16 & 12.05 \\
Number of tubes & 597 & 597 & 597 & 597 & 597 & 597 & 597 & 597 \\
Tube passes & 1.00 & 1.00 & 1.00 & 1.00 & 1.00 & 1.00 & 1.00 & 1.00 \\
Area (m²) & 255 & 298 & 872 & 133 & 303 & 364 & 433 & 429 \\
Tube pitch (mm) & 25.4 & 25.4 & 25.4 & 25.4 & 25.4 & 25.4 & 25.4 & 25.4 \\
Shell diameter (m) & 1.00 & 1.00 & 1.22 & 1.00 & 1.00 & 1.00 & 1.22 & 1.00 \\
Number of baffles & 30.0 & 34.0 & 38.0 & 15.0 & 22.0 & 26.0 & 32.0 & 31.0 \\
Baffle spacing (mm) & 340 & 240 & 650 & 240 & 390 & 390 & 382 & 390 \\
Inlet baffle spacing (mm) & 150 & 150 & 150 & 150 & 150 & 150 & 150 & 150 \\
Outlet baffle spacing (mm) & 150 & 150 & 150 & 150 & 150 & 150 & 150 & 150 \\
Baffle cut (\%) & 0.20 & 0.20 & 0.20 & 0.20 & 0.20 & 0.20 & 0.20 & 0.20 \\
Bundle clearance (mm) & 60.0 & 60.0 & 60.0 & 60.0 & 60.0 & 60.0 & 60.0 & 60.0 \\
Shell passes & 1.00 & 2.00 & 2.00 & 1.00 & 2.00 & 3.00 & 4.00 & 3.00 \\
\hline
\end{tabular}

Table 3: Input data for cold and hot utilities

\begin{tabular}{cccc}
\hline Stream & Inlet flow rate $\left(\mathrm{kg} \mathrm{s}^{-1}\right)$ & Inlet temperature $\left({ }^{\circ} \mathrm{C}\right)$ & Heat duty $(\mathrm{MW})$ \\
\hline Cold utility & 559 & 10 & 70 \\
$\mathrm{C} 1$ & 375 & - & 47 \\
$\mathrm{C} 2$ & 80 & - & 10 \\
$\mathrm{C} 3$ & 104 & - & 13 \\
Hot utility & 50 & 1500 & 95 \\
\hline
\end{tabular}


Table 4: Physical properties for heat exchangers

\begin{tabular}{|c|c|c|c|c|}
\hline Shell-side & E1 & $\mathrm{E} 2$ & E3 & $\mathrm{E} 4$ \\
\hline$\rho\left(\mathrm{kg} \mathrm{m}^{-3}\right)$ & 763.0 & 825 & 640 & 750 \\
\hline$c p\left(\mathrm{~J} \mathrm{~kg}^{-1} \mathrm{~K}^{-1}\right)$ & 2377 & 2408 & 2600 & 2900 \\
\hline$\lambda\left(\mathrm{W} \mathrm{K}^{-1}\right)$ & 0.117 & 0.110 & 0.110 & 0.088 \\
\hline$\mu(\mathrm{Pa} \mathrm{s})$ & $1.00 \times 10^{-3}$ & $4.00 \times 10^{-3}$ & $3.00 \times 10^{-4}$ & $1.00 \times 10^{-3}$ \\
\hline Shell-side & E5 & E6 & E7 & E8 \\
\hline$\rho\left(\mathrm{kg} \mathrm{m}^{-3}\right)$ & 738 & 875 & 732 & 830 \\
\hline$c p\left(\mathrm{~J} \mathrm{~kg}^{-1} \mathrm{~K}^{-1}\right)$ & 2800 & 2420 & 2870 & 2820 \\
\hline$\lambda\left(\mathrm{W} \mathrm{K}^{-1}\right)$ & 0.101 & 0.100 & 0.096 & 0.085 \\
\hline$\mu(\mathrm{Pa} \mathrm{s})$ & $7.00 \times 10^{-4}$ & $5.00 \times 10^{-4}$ & $2.00 \times 10^{-4}$ & $2.00 \times 10^{-3}$ \\
\hline Tube-side & E1 & $\mathrm{E} 2$ & E3 & $\mathrm{E} 4$ \\
\hline$\rho\left(\mathrm{kg} \mathrm{m}^{-3}\right)$ & 837.0 & 830 & 808 & 790 \\
\hline$c p\left(\mathrm{~J} \mathrm{~kg}^{-1} \mathrm{~K}^{-1}\right)$ & 1914 & 1994 & 2027 & 2385 \\
\hline$\lambda\left(\mathrm{W} \mathrm{K}^{-1}\right)$ & 0.128 & 0.0 .125 & 0.118 & 0.112 \\
\hline$\mu(\mathrm{Pa} \mathrm{s})$ & $8.50 \times 10^{-3}$ & $4.00 \times 10^{-3}$ & $2.00 \times 10^{-3}$ & $1.50 \times 10^{-3}$ \\
\hline Tube-side & E5 & E6 & E7 & E8 \\
\hline$\rho\left(\mathrm{kg} \mathrm{m}^{-3}\right)$ & 780 & 768 & 751 & 748 \\
\hline$c p\left(\mathrm{~J} \mathrm{~kg}^{-1} \mathrm{~K}^{-1}\right)$ & 2520 & 2560 & 2708 & 2842 \\
\hline$\lambda\left(\mathrm{W} \mathrm{K}^{-1}\right)$ & 0.109 & 0.106 & 0.0 .101 & 0.096 \\
\hline$\mu(\mathrm{Pa} \mathrm{s})$ & $1.20 \times 10^{-3}$ & $1.00 \times 10^{-3}$ & $0.80 \times 10^{-3}$ & $0.60 \times 10^{-3}$ \\
\hline
\end{tabular}

instruments such as flow meters and thermocouples. In the case of gross errors, constant magnitudes are added to specific measurements as a representation of a constant bias in these measurements, which can be related to flow rates or temperatures. For the detection of gross errors (i.e. the global test), a level of significance of $90 \%$ ( or $\delta=0.01$ ) is selected, as this value is commonly accepted in similar applications [14].

Fouling in each process-to-process heat exchanger is considered using two different fouling mechanisms. In the cold end of the pre-heat train (exchangers E1 to E4), deposition of waxes and particles occurs on both shell-side and tube side. A constant fouling rate model is assumed for this mechanism (see Equation 10). This mechanism is also assumed in the shell-side of each heat exchanger at the hot end of the pre-heat train (exchangers E5 to E8). In the tube-side of this heat exchangers, the chemical reaction fouling model proposed by Polley et. al [10] is considered (see Equation 11). Known values of the fouling model parameters for each mechanism are used for simulating the operating data. The values for both of these models are shown in Table 5. These data is then reconciled and the fouling model parameters for the pre-heat train are 
Table 5: Fouling model parameters used for simulation of operating data. From Rodriguez and Smith [35] and Polley et. al $[10]$

\begin{tabular}{lcccc}
\hline & $\alpha_{1}\left(\mathrm{~m}^{2} \mathrm{~K} \mathrm{~kW}^{-1} \mathrm{~h}^{-1}\right)$ & $E_{A}\left(\mathrm{~kJ} \mathrm{~mol}^{-1}\right)$ & $\gamma\left(\mathrm{m}^{2} \mathrm{~K} \mathrm{~kW}^{-1} \mathrm{~h}^{-1}\right)$ & $\alpha_{2}\left(\mathrm{~m}^{2} \mathrm{~K} \mathrm{~kW}^{-1} \mathrm{~h}^{-1}\right)$ \\
\hline $\mathrm{E} 1$ & $5.50 \times 10^{-4}$ & - & - & - \\
$\mathrm{E} 2$ & $5.50 \times 10^{-4}$ & - & - & - \\
$\mathrm{E} 3$ & $5.50 \times 10^{-4}$ & - & - & - \\
$\mathrm{E} 4$ & $5.50 \times 10^{-4}$ & - & $1.50 \times 10^{-9}$ & $1.00 \times 10^{6}$ \\
$\mathrm{E} 5$ & $5.50 \times 10^{-4}$ & 48.00 & $1.50 \times 10^{-9}$ & $1.00 \times 10^{6}$ \\
$\mathrm{E} 6$ & $5.50 \times 10^{-4}$ & 48.00 & $1.50 \times 10^{-9}$ & $1.00 \times 10^{6}$ \\
$\mathrm{E} 7$ & $5.50 \times 10^{-4}$ & 48.00 & $1.50 \times 10^{-9}$ & $1.00 \times 10^{6}$ \\
$\mathrm{E} 8$ & $5.50 \times 10^{-4}$ & 48.00 & &
\end{tabular}

back-calculated to test the resulting agreement of the parameter estimation algorithm.

The set of reconciled data is evenly divided into two parts; one for estimating the fouling model parameters (defined as the "estimation set"), and a second for comparing the total fouling resistance predictions using the estimated model parameters (defined as "prediction set"). The hybrid optimisation approach described in Section 4 is implemented using the optimisation parameters shown in Table 6, where the type of mutation function is selected in order to have a mutation function that determines the mutation fraction that adaptively changes according to the value of the objective function. These parameters are associated with the in-built function ga (Genetic Algorithm) in MATLAB. The population size and maximum number of generations depend on the number of optimisation variables. The value of the crossover fraction is chosen so that the algorithm prioritises a wide search to avoid local optima. Moreover, lower and upper bounds for each optimisation variable (in normalised form) are shown in Table 7. A broad range of values is used with the exception of the activation energy, as this value has been reported to be within the range of 38 and 59 $\mathrm{kJ} \mathrm{mol}^{-1}[34]$.

Table 6: Optimisation parameters for Genetic Algorithm

\begin{tabular}{cc}
\hline Parameter & Value \\
\hline Population size & 400 \\
Maximum number of generations & 400 \\
Crossover fraction & 0.20 \\
Optimisation variables & 4.00 \\
Mutation function & "Adaptive Feasible"
\end{tabular}

The calculations are made in a desktop computer with an Intel Core i5 processor of $3.20 \mathrm{GHz}$ and 8.00 


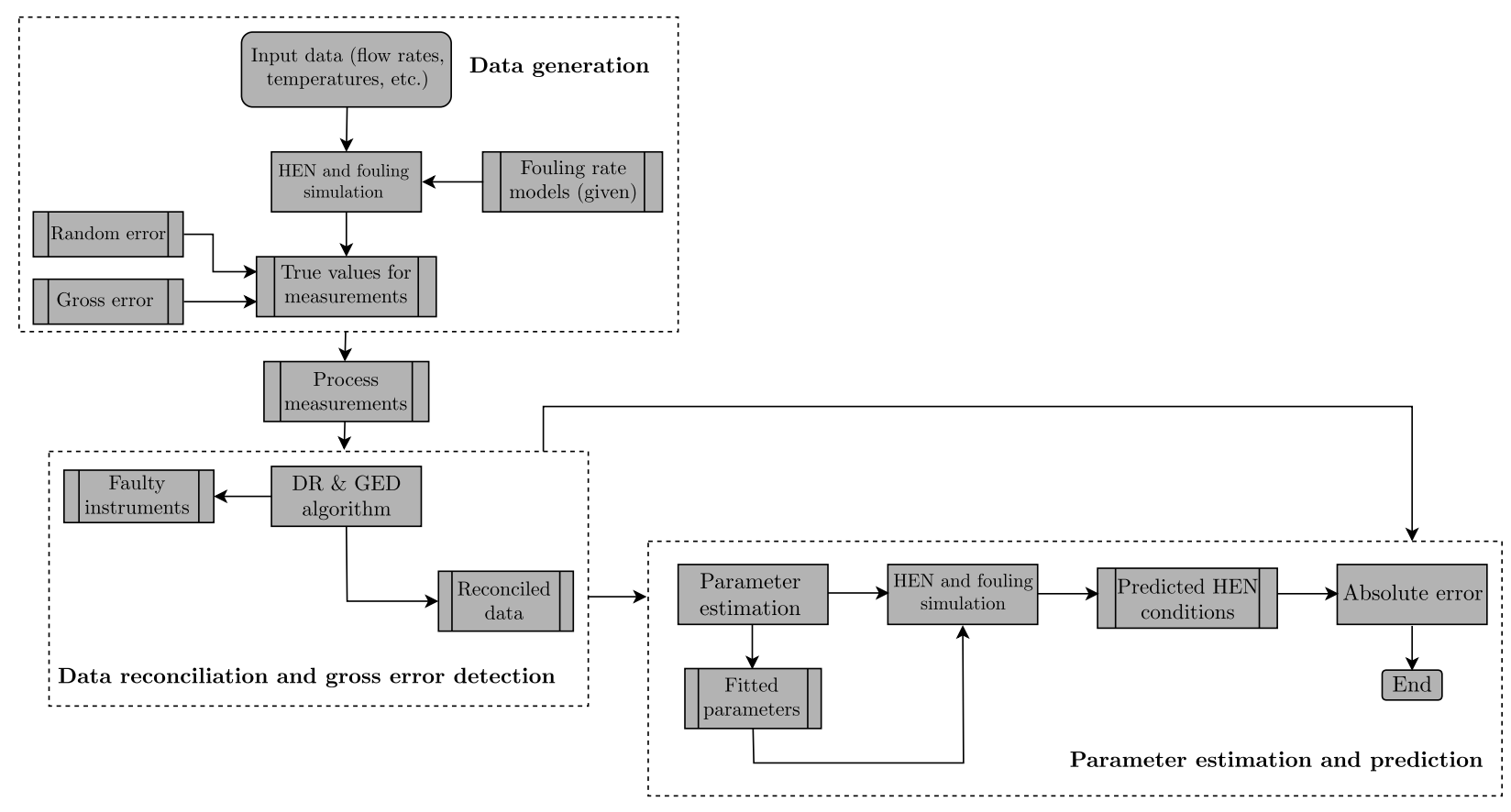

Figure 7: Schematic description of methodology

Table 7: Lower and upper bounds for normalised fouling model parameters

\begin{tabular}{ccc}
\hline Model parameter & Lower bound & Upper bound \\
\hline$\tilde{\alpha}_{1}$ & 0.00 & 100 \\
$\tilde{\alpha}_{2}$ & 0.00 & 100 \\
$\tilde{E}_{A}$ & 0.50 & 2.00 \\
$\tilde{\gamma}$ & 0.00 & 100 \\
\hline
\end{tabular}

GB of installed RAM. A summary of the entire methodology for this case study is depicted in Figure 7.

\subsection{Data Reconciliation and Gross Error Detection}

A constant value or gross error via measurement bias has been added in one flow rate and temperature within the pre-heat train. The flow rate bias is assumed to be contained in the Diesel stream, entering exchanger E4, whereas the temperature bias is assumed to be in the furnace inlet temperature. The values of these gross errors are defined with respect to the corresponding standard deviations for each measurement. The flow rate bias is equal to $12 \sigma_{m}$ and the temperature bias is equal to $12 \sigma_{T}$, which are equivalent to 6.00 $\mathrm{kg} \mathrm{s}^{-1}$ and $6.00^{\circ} \mathrm{C}$ respectively.

The results from the data reconciliation for the two biased measurements are presented in Figure 8. From this figure, it is clear that both sets of measurements are modified from their biased values (black curve) to their reconciled ones (blue curve). For both sets of measurements, the value of OPF has a value of 


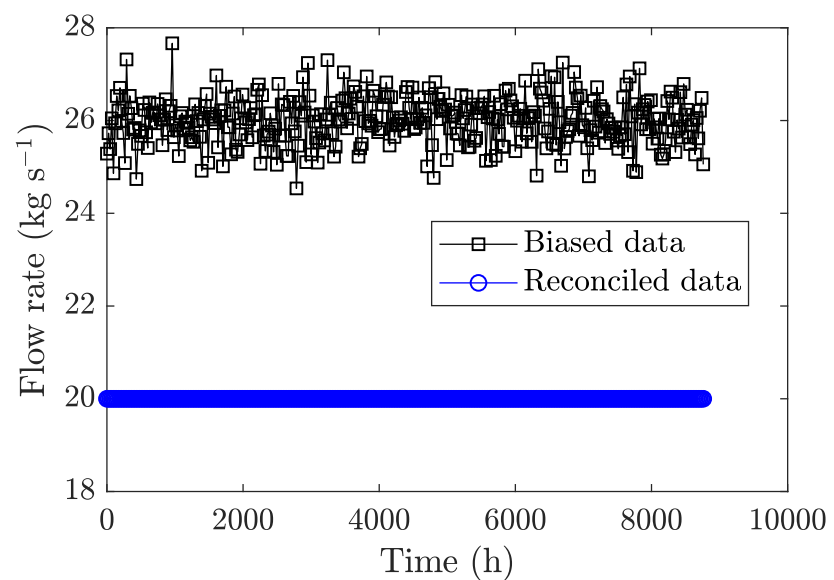

(a)

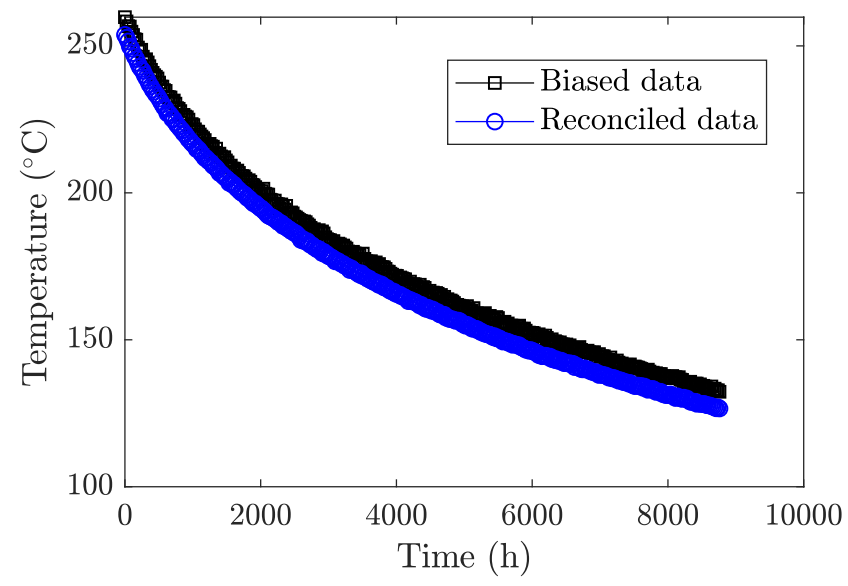

(b)

Figure 8: Data reconciliation and gross error detection results for Diesel flow rate (a) and furnace inlet temperature (b) measurements

1, indicating that these two values of gross errors are correctly located in all data-sets. The annual average estimation for both of these gross errors is shown in Table 8 .

The minimisation of random error for the all data-sets is assessed by calculating the reduction in standard deviation of the random error before and after reconciliation. The relative difference between these values provides an accurate indicator regarding the amount of random error that is reconciled. The percentage of reduction in standard deviation of the random error $\left(e r r_{\sigma}\right)$ is defined in Equation 26, where the superscripts before and after indicate the conditions of the data-sets relative to the data reconciliation.

$$
e r r_{\sigma}=\left(\frac{\sigma^{\text {before }}-\sigma^{\text {after }}}{\sigma^{\text {before }}}\right) \times 100
$$

The value of $\operatorname{err}_{\sigma}$ is calculated for each data-set (daily measurements) and an annual average value is 
Table 8: Average estimation of gross error values in the data-set

\begin{tabular}{ccc}
\hline Bias & Simulated value & Estimated value \\
\hline Diesel flow rate $\left(\mathrm{kg} \mathrm{s}^{-1}\right)$ & 6.00 & 5.99 \\
Furnace inlet temperature $\left({ }^{\circ} \mathrm{C}\right)$ & 4.00 & 5.97 \\
\hline
\end{tabular}

Table 9: Reduction is standard deviation of measurement error

\begin{tabular}{lccc}
\hline & $\sigma^{\text {before }}$ & $\sigma^{\text {after }}$ & Standard deviation reduction (\%) \\
\hline Flow rates $\left(\mathrm{kg} \mathrm{s}^{-1}\right)$ & 0.91 & 0.00 & 100.00 \\
Temperatures $\left({ }^{\circ} \mathrm{C}\right)$ & 0.91 & 0.18 & 80.72 \\
\hline
\end{tabular}

estimated. The results for the reduction of measurement error in the data reconciliation algorithm are shown in Table 9 .

The data reconciliation results in Table 9 indicate that the measurement error is completely minimised in the flow rate measurements, whereas in temperature measurements the measurement error is reduced by approximately $80 \%$. This result could be explained from the fact that temperature measurements are interrelated through nonlinear equations (energy balances), this is more challenging for the reconciliation algorithm to minimise the effect of random error. However, the overall performance is satisfactory as the mass and energy constraints are satisfied, as it is exhibited in the reduction in the standard deviation of the measurement error.

\subsection{Parameter estimation and prediction of fouling behaviour}

The quality of the reconciled data is tested and used in the parameter estimation algorithm described in Section 4. A crucial aspect regarding this process is the performance of the data reconciliation. If a significant amount of measurement error is still contained within the data, the accuracy of the estimated fouling model will not be sufficient for further predictions. Furthermore, when gross errors are present, the correct identification and mitigation (reconciliation) of such errors is paramount if accurate predictions are sought.

As previously mentioned in this section, an estimation data-set corresponding to half of the whole dataset is used for back-calculating the fouling model parameters for this particular pre-heat train. The results from this process are shown in Table 10. Some discrepancies are found among each parameter, as most parameters are correlated. This phenomenon is worse in the hot end of the pre-heat train (E5 to E8), where the parameters $\hat{\alpha}_{1}$ and $\hat{\gamma}$ are under-predicted. Nevertheless, each fouling model parameter is estimated within an acceptable range of magnitudes; in particular the activation energy $\hat{E}_{A}$. Note that the complexity of the solution directly depends on the fouling mechanisms (fouling rate models) that the heat exchangers are subject to. Different combinations of fouling models and model parameters add different levels of complexity 
Table 10: Fitted fouling model parameters and corresponding root mean square error $(R M S E)$

\begin{tabular}{cccccc}
\hline & $\hat{\alpha}_{1}\left(\mathrm{~m}^{2} \mathrm{~K} \mathrm{~kW}^{-1} \mathrm{~h}^{-1}\right)$ & $\hat{E}_{A}\left(\mathrm{~kJ} \mathrm{~mol}^{-1}\right)$ & $\hat{\gamma}\left(\mathrm{m}^{2} \mathrm{~K} \mathrm{~kW}^{-1} \mathrm{~h}^{-1}\right)$ & $\hat{\alpha}_{2}\left(\mathrm{~m}^{2} \mathrm{~K} \mathrm{~kW}^{-1} \mathrm{~h}^{-1}\right)$ & $R M S E\left(\mathrm{~m}^{2} \mathrm{~K} \mathrm{~kW}^{-1}\right)$ \\
\hline Base values & $5.50 \times 10^{-4}$ & 48.00 & - & $1.50 \times 10^{-9}$ & $1.00 \times 10^{6}$ \\
E1 & $5.50 \times 10^{-4}$ & - & - & - & - \\
E2 & $5.49 \times 10^{-4}$ & - & - & - & 0.035 \\
E3 & $5.50 \times 10^{-4}$ & - & - & - & 0.029 \\
E4 & $5.50 \times 10^{-4}$ & 41.03 & $4.90 \times 10^{-8}$ & $1.68 \times 10^{5}$ & 0.032 \\
E5 & $7.04 \times 10^{-4}$ & 51.87 & $8.75 \times 10^{-8}$ & $2.95 \times 10^{6}$ \\
E6 & $9.26 \times 10^{-4}$ & 49.28 & $8.86 \times 10^{-8}$ & $1.40 \times 10^{6}$ & 0.018 \\
E7 & $1.00 \times 10^{-3}$ & 48.91 & $9.00 \times 10^{-8}$ & $1.27 \times 10^{6}$ \\
E8 & $1.11 \times 10^{-3}$ & & & 0.030 \\
\hline
\end{tabular}

when estimating the fitted fouling models. The more model parameters are to be calculated for a specific heat exchanger, the greater the computational burden and impact on the accuracy of the parameter estimation algorithm.

The agreement between the measured and predicted fouling resistances for all heat exchangers can be used as a performance indicator for the parameter estimation algorithm. Parity plots for the overall fouling resistance of exchangers E1 to E8 are shown in Figure 9. The presence of remaining random error in the data is still present. However, the prediction of fouling resistance is in good agreement with the measured values, indicated by the parity plots presented in Figure 9. This result supports the performance obtained in the data reconciliation, and even though $20 \%$ of measurement error is still contained within the data, the overall prediction capabilities are acceptable. The maximum absolute difference between these sets of fouling resistances was found in exchanger $\mathrm{E} 8$, with an absolute difference of $0.35 \mathrm{~m}^{2} \mathrm{~K} \mathrm{~kW}^{-1}$.

A closer analysis of the predictions is made by calculating the absolute differences between the outlet conditions of the pre-heat train. The fitted models are used in a simulation of the heat exchanger network and the outlet temperatures in both sides of each heat exchanger are compared with the ones obtained from the data reconciliation (reconciled measurements). The comparisons for the tube-side outlet temperatures are shown in the histograms depicted in Figure 10. The differences between these sets of values indicate accurate predictions, where the maximum absolute difference is found in exchanger E8 with a value of $0.82^{\circ} \mathrm{C}$.

The absolute errors for the shell-side outlet temperatures in the pre-heat train are presented in Figure 11. The predictions differences are higher than those of the cold streams (tube-sides). Again, the maximum absolute difference is located in heat exchanger $\mathrm{E} 8$ with a value of $2.37^{\circ} \mathrm{C}$. The decrease in prediction accuracy is related to the parameter estimation algorithm, where the shell-side fouling model parameters for the heat exchangers in the hot end of the pre-heat train differ from the base values in one order of magnitude (see Table 10). Although these predictions are not as accurate as the ones presented in Figure 10, the overall prediction performance is still acceptable when predicting the overall fouling resistance of all heat exchangers in the pre-heat train, as most of the prediction errors are contained in the range of 0.00 and $0.50^{\circ} \mathrm{C}$ for both sides. 

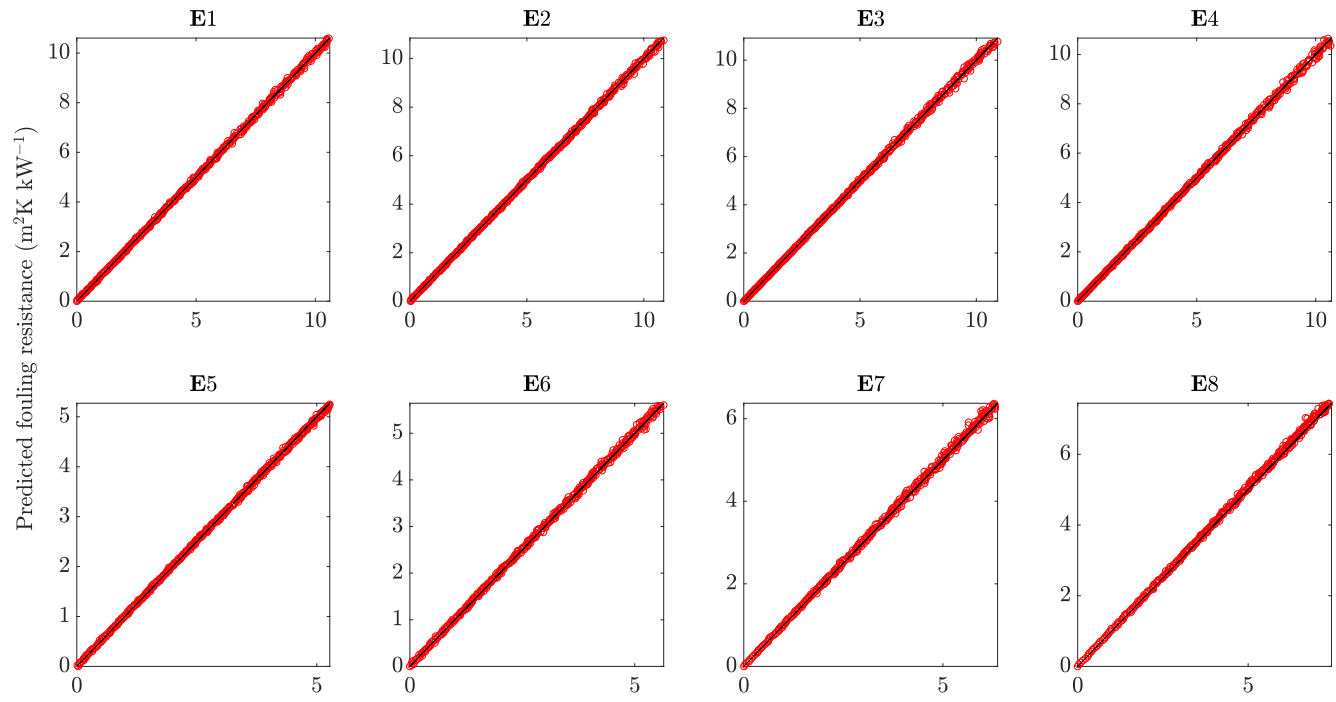

Figure 9: Measured and predicted fouling resistances for all heat exchangers in the network

The results from the case study show that operating data can be treated in a way such that they satisfy a set of process constraints and provide a reliable input for characterising the fouling behaviour of a pre-heat train when more than one fouling mechanism occurs in each heat exchanger. An important challenge to account for is the complexity associated with the fouling phenomenon in the shell-side, as these models are still in the process of development and more understanding of the underlying causes is needed for further improvements regarding the proposed methodology. 

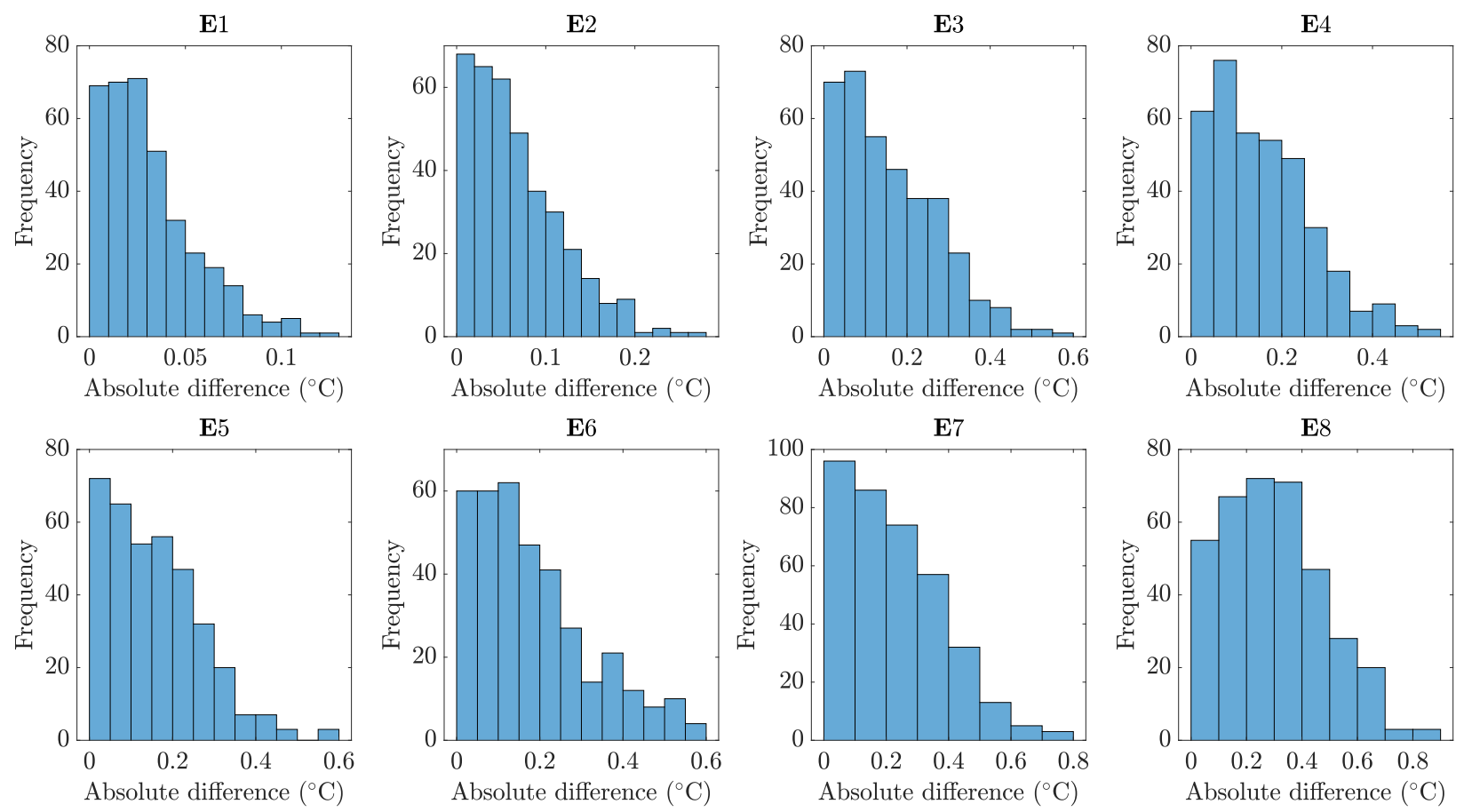

Figure 10: Absolute errors when comparing reconciled and predicted tube-side outlet temperatures in the pre-heat train 

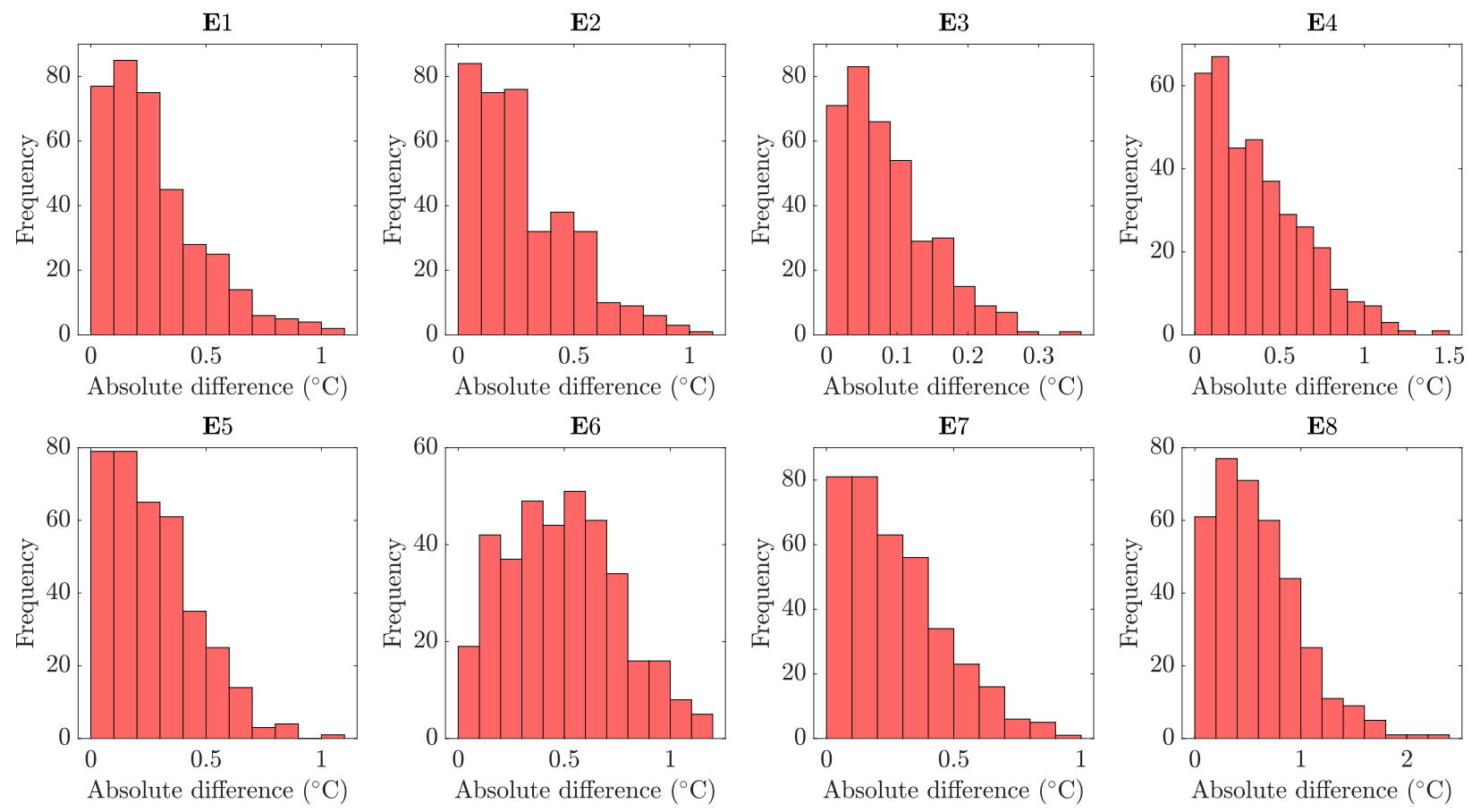

Figure 11: Absolute errors when comparing reconciled and predicted shell-side outlet temperatures in the pre-heat train

\section{Conclusions}

A new methodology for the calculation of fouling model parameters for a crude oil pre-heat train using reconciled data has been developed in this work. The interactions among streams and equipment is characterised via a simple but convenient formulation using linear algebra. This simulation approach provides enough flexibility for various topology arrangements, elements and temperature dependence of physical properties. Fouling is considered as a dynamic process, where the thermal performance of the pre-heat train varies accordingly with the development of fouling layers in both sides of each heat exchanger.

Data reconciliation and gross error detection are applied to the measured data, minimising the effect of measurement errors and faulty instruments. These algorithms allow for a detailed analysis of the propagation of measurement error and the effect of the presence of gross error on different process measurements, namely flow rates and temperatures. The inclusion of the identification of faulty measurement instruments into the HEN and fouling modelling represents a novel and innovative solution for the long-lasting concern regarding measurement reliability and selection of plant instrumentation. The reconciled data are further used for accurately estimating the fouling model parameters, which are strictly related to the crude oil being processed, meaning that the proposed methodology can be used whenever a new crude oil or crude oil blend is refined, if enough data are provided. 
A case study has been presented, and the results indicated a successful separation between shell-side and tube-side fouling mechanisms by calculating their individual contributions into the overall fouling resistance. Moreover, the use of the data reconciliation and gross error detection methods were able to mitigate the effect of random errors and to locate, identify and estimate a set of two gross errors in two different measurements. The fitted fouling parameters presented a good agreement with the initial simulations, where accurate predictions for fouling resistance and outlet temperature were obtained. Note that these predictions were calculated using reconciled process variables rather than fouling resistances, which contribute additional errors when no data reconciliation is considered.

A study is needed where the proposed methodology is applied using real operating data. In this work, a steady-state data reconciliation method was chosen. This assumption should be tested and updated to consider the dynamic changes when monitoring a crude oil pre-heating process. Furthermore, the parameter estimation method is still limited by the current understanding and modelling of fouling rates in both sides of heat exchangers. The authors acknowledge the on-going progress in this field, and modifications are to be made consistently with the state-of-the-art modelling approaches for shell-side and tube-side fouling mechanisms. Nonetheless, the study presented in this work delivers enough potential for further applications in the areas of design, retrofit and optimisation of heat exchanger networks based on historical or on-line data.

\section{Acknowledgements}

The authors gratefully acknowledge the Chilean National Commission for Scientific and Technological Research (CONICyT) for the financial support granted for the development of this work.

\section{Appendix A. HEN Modelling}

\section{Appendix A.1. Heat Exchangers}

The mass balance for cold-side and hot-side of a single heat exchanger in the network is defined in Equations A.1 and A.2. The subscripts $i$ and $o$ indicate inlet or outlet streams.

$$
\begin{aligned}
& m_{c, i}-m_{c, o}=0 \\
& m_{h, i}-m_{h, o}=0
\end{aligned}
$$

The matrix representation for the mass balance of Equations A.1 and A.2 is shown in Equations A.3 and A.4. Each set of mass balance has a total number of $N^{H E}$ equations. 


$$
\begin{aligned}
& \boldsymbol{M}_{c}^{H E} \boldsymbol{m}_{c}=\mathbf{0} \\
& \boldsymbol{M}_{c}^{H E} \boldsymbol{m}_{h}=\mathbf{0}
\end{aligned}
$$

The energy balance equations are formulated using the concepts of thermal effectiveness $(\varepsilon)$ and number of transfer units $(N T U)$, also known as the $\varepsilon-N T U$ method [38]. The thermal effectiveness is defined as the ratio between the heat duty of the heat exchanger $(Q)$ and its maximum amount of heat that could be exchanged considering the highest temperature difference (e.g. $\left.\left(T_{h, i}-T_{c, i}\right)\right)$. The value of $\varepsilon$ is calculated using Equation A.5. In this Equation, $\overline{C P}$ is the average heat capacity flow rate $(\overline{C P}=m \overline{c p}$, where $\overline{c p}$ is the average heat capacity in the temperature interval $\left.\left[T_{i}, T_{o}\right]\right)$. The subscript min indicates the stream (cold or hot) presenting the lower value of $\overline{C P}$. On the other hand, the value of $N T U$ is calculated using Equation A.6, where $U_{d}$ and $A$ are the overall heat transfer coefficient and the heat transfer area of the heat exchanger. Two more variables are needed to complete this formulation. The first one is the heat capacity flow rate ratio $\left(C_{r}\right)$, which is defined as the ratio between the values of the higher and lower heat capacity flow rates. The second one is a binary variable that identifies if either the cold or the hot stream presents the lower value of $\overline{C P}$. This binary variable is defined as $y_{r}$ and its value will be equal to 1 if the hot stream is the stream with the minimum heat capacity flow rate value. Otherwise, when the lower value of $\overline{C P}$ is in the cold stream, $y_{r}$ will have a value of zero. The generalisation of the energy balance equations is shown in Equation A.7.

$$
\begin{gathered}
\varepsilon=\frac{Q}{\overline{C P_{\min }\left(T_{h, i}-T_{c, i}\right)}} \\
N T U=\frac{U_{d} A}{\overline{C P}_{\min }} \\
{\left[\begin{array}{cccc}
\varepsilon+\left(y_{r}+1\right) & -\left(y_{r}-1\right) & y_{r} & -y_{r} \\
C_{r}\left(y_{r}-1\right)+y_{r} & -C_{r}\left(y_{r}-1\right)-y_{r} & C_{r} y_{r}+\left(y_{r}-1\right) & -C_{r} y_{r}+\left(y_{r}-1\right)
\end{array}\right]\left[\begin{array}{c}
T_{c, i} \\
T_{c, o} \\
T_{h, i} \\
T_{h, o}
\end{array}\right]=\mathbf{0}}
\end{gathered}
$$

Using the incidence matrix $\boldsymbol{M}$, the energy balance equations are defined in Equations A.8 and A.9.

$$
\begin{array}{r}
E c i T c i+E c o T c o+E h i T h i+E h o T h o=0 \\
\text { RcTci-RcTco+RhThi-RhTho}=0
\end{array}
$$


The auxiliary matrices $\boldsymbol{E c i}, \boldsymbol{E c o}, \boldsymbol{E h i}, \boldsymbol{E h o}, \boldsymbol{R} \boldsymbol{c}$ and $\boldsymbol{R h}$ in Equation A.8 and Equation A.9 are used for simplifying the formulation of the energy balance equations. All these matrices are diagonal matrices, where the $i$ th element of their main diagonals is defined in Equations A.10 to A.15.

$$
\begin{aligned}
& (\boldsymbol{E c i})_{i \mathrm{th}}=\varepsilon+\left(y_{r}-1\right) \\
& (\boldsymbol{E c o o})_{i \mathrm{th}}=-\left(y_{r}-1\right) \\
& (\boldsymbol{E h i i})_{i \mathrm{th}}=y_{r}-\varepsilon \\
& (\boldsymbol{E h} \boldsymbol{o})_{i \mathrm{th}}=-y_{r} \\
& (\boldsymbol{R c})_{i \mathrm{th}}=C_{r}\left(y_{r}-1\right)+y \\
& (\boldsymbol{R h})_{i \mathrm{th}}=C_{r} y_{r}+\left(y_{r}-1\right)
\end{aligned}
$$

The auxiliary vectors $\boldsymbol{T c i}, \boldsymbol{T c o}, \boldsymbol{T h i}$ and $\boldsymbol{T h \boldsymbol { o }}$ are defined in Equations A.16 to A.19. These vectors contain the inlet and outlet temperatures of each heat exchanger in the network. The subscripts + and indicate the inlets and outlets of the corresponding entries in the incidence matrix $\boldsymbol{M}$.

$$
\begin{aligned}
& \boldsymbol{T c i}=\left(\boldsymbol{M}_{c}^{H E}\right)_{+} \boldsymbol{T}_{c} \\
& \boldsymbol{T c o}=-\left(\boldsymbol{M}_{c}^{H E}\right)_{-} \boldsymbol{T}_{c} \\
& \boldsymbol{T h i}=\left(\boldsymbol{M}_{h}^{H E}\right)_{+} \boldsymbol{T}_{h} \\
& \boldsymbol{T h \boldsymbol { o }}=-\left(\boldsymbol{M}_{h}^{H E}\right)_{-} \boldsymbol{T}_{h}
\end{aligned}
$$

Combining Equations A.16 to A.19 with Equations A.8 and A.9, the energy balance formulation is obtained. These re-arrangements are shown in Equations A.20 and A.21. Each set of energy balance has a total number of $N^{H E}$ equations.

$$
\begin{array}{r}
{\left[(\boldsymbol{E c i})\left(\boldsymbol{M}_{c}^{H E}\right)_{+}-(\boldsymbol{E c o})\left(\boldsymbol{M}_{c}^{H E}\right)_{-}\right] \boldsymbol{T}_{c}+\left[(\boldsymbol{E h} \boldsymbol{i})\left(\boldsymbol{M}_{h}^{H E}\right)_{+}-(\boldsymbol{E h o})\left(\boldsymbol{M}_{h}^{H E}\right)_{-}\right] \boldsymbol{T}_{h}=\mathbf{0}} \\
{\left[(\boldsymbol{R} \boldsymbol{c})\left(\boldsymbol{M}_{c}^{H E}\right)\right] \boldsymbol{T}_{c}+\left[(\boldsymbol{R h})\left(\boldsymbol{M}_{h}^{H E}\right)\right] \boldsymbol{T}_{h}=\mathbf{0}}
\end{array}
$$

\section{Appendix A.2. Mixers}

Mixers join together several inlet streams into a single outlet stream. They can be installed in any cold or hot stream. Mass and energy balance equations for a single mixer are defined in Equations A.22 and A.23. The subscripts 1,2 and 3 indicate the different inlet streams of the mixer. 


$$
\begin{array}{r}
m_{i, 1}+m_{i, 2}+m_{i, 3}+\cdots-m_{o}=0 \\
C P_{i, 1} T_{i, 1}+C P_{i, 2} T_{i, 2}+C P_{i, 3} T_{i, 3}+\cdots-C P_{o} T_{o}=0
\end{array}
$$

The matrix representation for the mass and energy balances of a mixer unit is described in Equations A.24 and A.25 respectively.

$$
\begin{aligned}
\boldsymbol{M}^{M X} \boldsymbol{m} & =\mathbf{0} \\
\boldsymbol{M}^{M X}[\operatorname{diag}(\boldsymbol{C P})] \boldsymbol{T} & =\mathbf{0}
\end{aligned}
$$

Where $\boldsymbol{C P}$ is a vector containing the heat capacity flow rates of each stream in the network. The total number of equations for each set is $N^{M X}$. The operator diag converts a vector into a diagonal matrix, where its main diagonal contains the elements of such vector.

\section{Appendix A.3. Splitters}

Following the assumptions proposed by de Oliveira Filho et al. [31], a splitter divides a single inlet stream into two different outlet streams. If more than two outlet streams are needed, a series of splitters can be used. Mass and energy balance models for a single splitter are shown in Equations A.26 to A.29.

$$
\begin{array}{r}
m_{i}-m_{o, 1}-m_{o, 2}=0 \\
\phi m_{i}-m_{o, 1}=0 \\
C P_{i} T_{i}-C P_{o, 1} T_{o, 1}-C P_{o, 2} T_{o, 2}=0 \\
T_{i}=T_{o, 1}=T_{o, 2}
\end{array}
$$

where $\phi$ is the fraction of the inlet stream $m_{i}$ that flows into the outlet stream $m_{o, 1}$. The mass and energy equations in matrix form are presented in Equations A.30 to A.33. There are a total of $2 N^{S P}$ equations.

$$
\begin{aligned}
\boldsymbol{M}^{\boldsymbol{S P}} \boldsymbol{m} & =\mathbf{0} \\
{\left[\operatorname{diag}(\boldsymbol{\phi}) \boldsymbol{M}_{+}^{S P}-\boldsymbol{S P}\right] \boldsymbol{m} } & =\mathbf{0} \\
\boldsymbol{M}^{S P}[\operatorname{diag}(\boldsymbol{C P})] \boldsymbol{T} & =\mathbf{0} \\
{\left[\boldsymbol{M}_{+}^{S P}-\boldsymbol{S P}\right] \boldsymbol{T} } & =\mathbf{0}
\end{aligned}
$$

The split fraction $\phi$ is introduced in vector form in Equation A.31 using the vector $\phi$ of dimensions $\left(N^{S P} \times 1\right)$. A different vector, defined as $\boldsymbol{a}$ is also introduced in order to facilitate the formulation of the 
conservation equations using the incidence matrix. This vector indicates the corresponding outlet stream index related to each split fraction contained in vector $\boldsymbol{\phi}$. The matrix $\boldsymbol{S P}$ (dimensions $N^{S P} \times S$ ) is defined such that $(\boldsymbol{S P})_{i, j}=1$ if $(\boldsymbol{a})_{i}=j$; otherwise $(\boldsymbol{S P})_{i, j}=0$. The subscript + represents the same concept as indicated in Appendix A.1.

\section{Appendix A.4. Supply and Demand Units}

These units represent operations that are carried out upstream and downstream of the pre-heat train (i.e. crude storage, atmospheric distillation respectively). For a single supply or demand unit $k$, mass and energy balance formulations are defined in Equations A.34 and A.35. The vectors for flow rate and temperatures of supply and demand units $\boldsymbol{n}$ and $\boldsymbol{V}$ are used in these Equations.

$$
\begin{aligned}
m_{k}-n_{k} & =0 \\
T_{k}-V_{k} & =0
\end{aligned}
$$

The matrix representation of the mass and energy balance for supply and demand units is shown in Equations A.36 and A.37. Each set of has a total number of $\left(N^{P S}+N^{P D}\right)$ equations.

$$
\begin{aligned}
& {\left[\begin{array}{c}
\boldsymbol{M}^{P S} \\
-\boldsymbol{M}^{P D}
\end{array}\right] \boldsymbol{m}+\boldsymbol{n}=\mathbf{0}} \\
& {\left[\begin{array}{c}
\boldsymbol{M}^{P S} \\
-\boldsymbol{M}^{P D}
\end{array}\right] \boldsymbol{T}+\boldsymbol{V}=\mathbf{0}}
\end{aligned}
$$

\section{Appendix A.5. Supply Units Specifications}

Each supply unit presents its own value for flow rate and temperature. Mass and energy balance equations are shown in Equations A.38 and A.39. Specification vectors $\left(\boldsymbol{n}^{P S}\right)^{*}$ and $\left(\boldsymbol{V}^{P S}\right)^{*}$ are used. There are a total of $N^{P S}$ equations per set of balance model.

$$
\begin{aligned}
\boldsymbol{n}^{P S}-\left(\boldsymbol{n}^{P S}\right)^{*} & =\mathbf{0} \\
\boldsymbol{V}^{P S}-\left(\boldsymbol{V}^{P S}\right)^{*} & =\mathbf{0}
\end{aligned}
$$

\section{Appendix A.6. Desalter}

These units are considered as units that modify the temperature or enthalpy of a specific stream, without significantly changing their flow rate. Mass and energy balance for a single unit are presented in Equations A.40 and A.41. 


$$
\begin{aligned}
& m_{i}-m_{o}=0 \\
& T_{i}-T_{o}=\Delta T^{U P}
\end{aligned}
$$

where $\Delta T^{U P}$ (dimensions $N^{U P} \times 1$ ) is a vector containing the temperature differences for each operational unit within the network. The matrix representation of these units is presented in Equations A.42 and A.43. There is a total of $N^{U P}$ of equations for each balance.

$$
\begin{aligned}
& \boldsymbol{M}^{U P} \boldsymbol{m}=\mathbf{0} \\
& \boldsymbol{M}^{U P} \boldsymbol{T}=\boldsymbol{\Delta} \boldsymbol{T}^{U P}
\end{aligned}
$$

\section{Appendix A.7. Cold and Hot Utilities}

Mass balance equations for cold and hot utilities, using the incidence matrix are shown in Equations A.44 and A.45.

$$
\begin{aligned}
& \boldsymbol{M}_{c}^{U T} \boldsymbol{m}_{c}=\mathbf{0} \\
& \boldsymbol{M}_{h}^{U T} \boldsymbol{m}_{h}=\mathbf{0}
\end{aligned}
$$

The energy balance is specified in terms of the heat duty of each utility $\boldsymbol{Q}^{U}$ (dimension $N^{U T} \times 1$ ), instead of the total equipment area as in the case of process-to-process heat exchangers (see Section Appendix A.1). The matrix representation of the energy balance for each type of utility is presented in Equations A.46 and A.47.

$$
\begin{aligned}
- & {\left[\operatorname{diag}\left(\overline{\boldsymbol{C P}}_{\boldsymbol{c}}^{U \boldsymbol{T}}\right)\right] \boldsymbol{M}_{c}^{U T} \boldsymbol{T}_{\boldsymbol{c}}=\boldsymbol{Q}^{U} } \\
& {\left[\operatorname{diag}\left(\overline{\boldsymbol{C P}}_{\boldsymbol{h}}^{U \boldsymbol{T}}\right)\right] \boldsymbol{M}_{h}^{U T} \boldsymbol{T}_{\boldsymbol{h}}=\boldsymbol{Q}^{U} }
\end{aligned}
$$

where $\left(\overline{\boldsymbol{C P}}^{U T}\right)^{T}=\left[\left(\overline{\boldsymbol{C P}}_{c}^{U T}\right)^{T}\left(\overline{\boldsymbol{C P}}_{h}^{U T}\right)^{T}\right]$ is a vector containing the average heat capacity flow rate for each cold and hot utility.

\section{Nomenclature}

\section{Symbols}

A

$b$
Matrix of coefficients for HEN mass balance

Vector of solutions for HEN mass balance 


\begin{tabular}{|c|c|}
\hline $\boldsymbol{B}_{\xi}$ & Bias location matrix \\
\hline$\overline{C P}$ & Vector of average heat capacity flow rates \\
\hline$C P$ & Vector of heat capacity flow rates \\
\hline$C$ & Matrix of coefficients for HEN energy balance \\
\hline$d$ & Vector of solutions for HEN energy balance \\
\hline Eci, Eco, Ehi, Eho & Auxiliary matrices for HEN energy balance \\
\hline$g_{\xi}$ & Vector of bias magnitudes \\
\hline $\boldsymbol{I}$ & Identity matrix \\
\hline$m$ & Vector of HEN internal mass flow rates \\
\hline$M$ & Incidence matrix for HEN structure \\
\hline$n$ & Vector of HEN external mass flow rates \\
\hline$p$ & Vector of fouling model parameters \\
\hline$Q$ & Vector of HEN heat duties \\
\hline$q_{\xi}$ & Vector of constraints residuals for gross error detection \\
\hline$R c, R h$ & Auxiliary matrices for HEN energy balance \\
\hline$S P$ & Split fraction matrix \\
\hline$T$ & Vector of internal HEN temperatures \\
\hline Tci, Tco, Thi, Tho & Auxiliary matrices for HEN energy balance \\
\hline $\boldsymbol{V}$ & Vector of external HEN temperatures \\
\hline$x$ & Vector of variables for HEN mass balance \\
\hline$x_{m}$ & Vector of measured variables \\
\hline$x_{r}$ & Vector of reconciled variables \\
\hline$z$ & Vector of variables for HEN energy balance \\
\hline$A$ & Heat transfer area \\
\hline$\overline{C P}$ & Average heat capacity flow rate \\
\hline$C P$ & Heat capacity flow rate \\
\hline$\overline{c p}$ & Average heat capacity \\
\hline$c p$ & Heat capacity \\
\hline$C_{r}$ & Heat capacity flow rate ratio \\
\hline$d_{\text {in }}$ & Inlet tube diameter \\
\hline$d_{\text {out }}$ & Outlet tube diameter \\
\hline$E_{A}$ & Activation energy \\
\hline $\operatorname{err}_{\sigma}$ & Reduction percentage of standard deviation in random error \\
\hline$h$ & Local heat transfer coefficient \\
\hline$m$ & HEN internal mass flow rate \\
\hline
\end{tabular}




\section{Greek Letters}

HEN external mass flow rate

Element number in HEN

Number of transfer units

Overall power function

Prandtl number

Heat duty

Random error magnitude

Reynolds number

Fouling resistance

Ideal gas constant

Root mean square error

Stream number in HEN

Time

HEN stream temperature

Clean overall heat transfer coefficient

Overall heat transfer coefficient for fouling conditions

Binary variable for HEN energy balance

Vector of temperature difference for HEN unit operations

Vector of split fractions

Covariance matrix of constraints residuals

Covariance matrix of measurement error

Constant fouling rate parameter

Chemical reaction fouling rate formation parameter

Level of significance for gross error detection

Temperature difference specification

Thermal effectiveness

Chemical reaction fouling rate removal parameter

Thermal conductivity

Dynamic viscosity

Degrees of freedom for gross error detection

Split fraction

Density

Standard deviation 


\section{Subscripts}

$+$

$c$

$h$

$i$

j

$m$

mean

$\min$

$O$

shell

$T$

tube

W

\section{Superscripts}

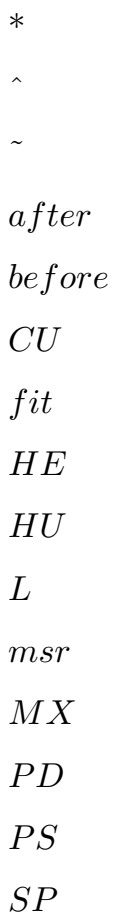

Test function for global test

Threshold value for test function in global test

Total measurement error

Matrix with negative entries

Matrix with positive entries

Cold stream

Hot stream

Matrix entry, inlet

Matrix entry

Mass flow rate measurement

Mean value

Minimum value

Outlet

Shell-side

Temperature measurement

Tube-side

Tube-wall

Specification value

Fitted fouling model parameter

Normalised fouling model parameter

After data reconciliation

Before data reconciliation

Cold utility

Fitted value

Heat exchanger

Hot utility

Lower bound

Measurement

Mixer

Demand unit

Supply unit

Splitter 


\section{References}

[1] M. Ledezma-Martínez, M. Jobson, R. Smith, Simulation-optimization-based design of crude oil distillation systems with preflash units, Industrial \& Engineering Chemistry Research 57 (2018) 9821-9830.

[2] C. Panchal, E.-P. Huangfu, Effects of mitigating fouling on the energy efficiency of crude-oil distillation, Heat Transfer Engineering 21 (2000) 3-9.

[3] S. Ahmad, G. Polley, E. Petela, Retrofit of heat exchanger networks subject to pressure drop constraints, in: AIChE Spring Meeting, Paper 34a, 1989.

[4] E. M. Ishiyama, S. J. Pugh, B. Paterson, G. T. Polley, J. Kennedy, D. I. Wilson, Management of crude preheat trains subject to fouling, Heat Transfer Engineering 34 (2013) 692-701.

[5] N. Epstein, Thinking about heat transfer fouling: A 5x5 matrix, Heat Transfer Engineering 4 (1983) 43-56.

[6] S. Macchietto, G. F. Hewitt, F. Coletti, B. D. Crittenden, D. R. Dugwell, A. Galindo, G. Jackson, R. Kandiyoti, S. G. Kazarian, P. F. Luckham, O. K. Matar, M. Millan-Agorio, E. A. Müller, W. Paterson, S. J. Pugh, S. M. Richardson, D. I. Wilson, Fouling in crude oil preheat trains: A systematic solution to an old problem, Heat Transfer Engineering 32 (2011) $197-215$.

[7] A. Young, S. Venditti, C. Berrueco, M. Yang, A. Waters, H. Davies, S. Hill, M. Millan, B. D. Crittenden, Characterization of crude oils and their fouling deposits using a batch stirred cell system, Heat Transfer Engineering 32 (2011) 216-227.

[8] D. J. Kukulka, M. Devgun, Fluid temperature and velocity effect on fouling, Applied Thermal Engineering 27 (2007) $2732-2744$.

[9] G. T. Polley, D. I. Wilson, B. L. Yeap, S. J. Pugh, Evaluation of laboratory crude oil threshold fouling data for application to refinery pre-heat trains, Applied Thermal Engineering 22 (2002) 777-788.

[10] G. T. Polley, D. I. Wilson, S. J. Pugh, E. Petitjean, Extraction of crude oil fouling model parameters from plant exchanger monitoring, Heat Transfer Engineering 28 (2007) 185-192.

[11] A. Martini, D. Coco, A. Sorce, A. Traverso, P. Levorato, Gross error detection based on serial elimination: Applications to an industrial gas turbine, in: Proceedings of ASME Turbo Expo 2014: Turbine Technical Conference and Exposition, volume 3A, 2014, p. V03AT07A024.

[12] M. Szega, An improvement of measurements reliability in thermal processes by application of the advanced data reconciliation method with the use of fuzzy uncertainties of measurements, Energy 141 (2017) 2490-2498.

[13] M. Szega, Extended applications of the advanced data validation and reconciliation method in studies of energy conversion processes, Energy 161 (2018) 156-171.

[14] S. Narasimhan, C. Jordache, Data reconciliation \& gross error detection: An intelligent use of process data, Gulf Publishing Co., Houston, Texas, USA, 2000.

[15] F. Madron, A new approach to the identification of gross errors in chemical engineering measurements, Chemical Engineering Science 40 (1985) 1855 - 1860.

[16] R. S. Mah, G. M. Stanley, D. M. Downing, Reconciliation and rectification of process flow and inventory data, Industrial \& Engineering Chemistry Process Design and Development 15 (1976) 175-183.

[17] R. S. H. Mah, A. C. Tamhane, Detection of gross errors in process data, AIChE Journal 28 (1982) 828-830.

[18] S. Narasimhan, R. S. H. Mah, Generalized likelihood ratio method for gross error identification, AIChE Journal 33 (1987) $1514-1521$. 
[19] J. A. Romagnoli, M. C. Sánchez, Data processing and reconciliation for chemical process operations, Academic Press, Inc., Orlando, Florida, USA, 1999.

[20] M. Sánchez, J. Romagnoli, Q. Jiang, M. Bagajewicz, Simultaneous estimation of biases and leaks in process plants, Computers \& Chemical Engineering 23 (1999) 841-857.

[21] D. K. Rollins, J. F. Davis, Unbiased estimation of gross errors in process measurements, AIChE Journal 38 (1992) $563-572$.

[22] F. Smaïli, V. S. Vassiliadis, D. I. Wilson, Mitigation of fouling in refinery heat exchanger networks by optimal management of cleaning, Energy \& Fuels 15 (2001) 1038-1056.

[23] H. Ijaz, U. M. Ati, V. Mahalec, Heat exchanger network simulation, data reconciliation \& optimization, Applied Thermal Engineering 52 (2013) 328-335.

[24] E. M. Ishiyama, J. Kennedy, S. J. Pugh, Fouling management of thermal cracking units, Heat Transfer Engineering 38 (2017) 694-702.

[25] X. Jiang, P. Liu, Z. Li, Data reconciliation and gross error detection for operational data in power plants, Energy 75 (2014) 14-23.

[26] F. Coletti, S. Macchietto, A dynamic, distributed model of shell-and-tube heat exchangers undergoing crude oil fouling, Industrial \& Engineering Chemistry Research 50 (2011) 4515-4533.

[27] B. C. G. Assis, J. C. Lemos, F. S. Liporace, S. G. Oliveira, E. M. Queiroz, F. L. P. Pessoa, A. L. H. Costa, Dynamic optimization of the flow rate distribution in heat exchanger networks for fouling mitigation, Industrial \& Engineering Chemistry Research 54 (2015) 6497-6507.

[28] E. Diaz-Bejarano, F. Coletti, S. Macchietto, A new dynamic model of crude oil fouling deposits and its application to the simulation of fouling-cleaning cycles, AIChE Journal 62 (2015) 90-107.

[29] E. Diaz-Bejarano, F. Coletti, S. Macchietto, Modeling and prediction of shell-side fouling in shell-and-tube heat exchangers, Heat Transfer Engineering 0 (2018) 1-17.

[30] A. L. H. Costa, V. B. G. Tavares, J. L. Borges, E. M. Queiroz, F. L. P. Pessoa, F. dos Santos Liporace, S. G. de Oliveira, Parameter estimation of fouling models in crude preheat trains, Heat Transfer Engineering 34 (2013) 683-691.

[31] L. O. de Oliveira Filho, E. M. Queiroz, A. L. Costa, A matrix approach for steady-state simulation of heat exchanger networks, Applied Thermal Engineering 27 (2007) 2385-2393.

[32] L. M. Ochoa-Estopier, M. Jobson, L. Chen, C. A. Rodríguez-Forero, R. Smith, Optimization of heat-integrated crude oil distillation systems. part ii: Heat exchanger network retrofit model, Industrial \& Engineering Chemistry Research 54 (2015) 5001-5017.

[33] Y. Wang, M. Pan, I. Bulatov, R. Smith, J.-K. Kim, Application of intensified heat transfer for the retrofit of heat exchanger network, Applied Energy 89 (2012) 45-59.

[34] B. Yeap, D. Wilson, G. Polley, S. Pugh, Mitigation of crude oil refinery heat exchanger fouling through retrofits based on thermo-hydraulic fouling models, Chemical Engineering Research and Design 82 (2004) 53-71.

[35] C. Rodriguez, R. Smith, Optimization of operating conditions for mitigating fouling in heat exchanger networks, Chemical Engineering Research and Design 85 (2007) 839-851.

[36] M. J. Bagajewicz, Q. Jiang, Gross error modeling and detection in plant linear dynamic reconciliation, Computers \& Chemical Engineering 22 (1998) 1789-1809.

[37] D. E. Goldberg, Genetic algorithms in search, optimization and machine learning, Addison-Wesley Longman Publishing Co., Inc., Boston, MA, USA, 1989.

[38] E. Cao, Heat transfer in process engineering, McGraw-Hill Professional, 2010. 